\title{
Progress in Bio-inspired Anti-solid Particle Erosion Materials: Learning from Nature but Going beyond Nature
}

\author{
Shuaijun Zhang ${ }^{1}$, Junqiu Zhang ${ }^{1}$, Bin Zhu ${ }^{2}$, Shichao Niu ${ }^{1 *}$ (D), Zhiwu Han ${ }^{1 *}$ and Luquan Ren ${ }^{1}$
}

\begin{abstract}
Solid particle erosion is a common phenomenon in engineering fields, such as manufacturing, energy, military and aviation. However, with the rising industrial requirements, the development of anti-solid particle erosion materials remains a great challenge. After billions of years of evolution, several natural materials exhibit unique and exceptional solid particle erosion resistance. These materials achieved the same excellent solid particle erosion resistance performance through diversified strategies. This resistance arises from their micro/nanoscale surface structure and interface material properties, which provide inspiration for novel multiple solutions to solid particle erosion. Here, this review first summarizes the recent significant process in the research of natural anti-solid particle erosion materials and their general design principles. According to these principles, several erosion-resistant structures are available. Combined with advanced micro/nanomanufacturing technologies, several artificial anti-solid particle erosion materials have been obtained. Then, the potential applications of anti-solid particle erosion materials are prospected. Finally, the remaining challenges and promising breakthroughs regarding anti-solid particle erosion materials are briefly discussed.
\end{abstract}

Keywords: Bio-inspired materials, Solid particle erosion, Surface structures, Micro/nanomanufacturing technologies, Applications

\section{Introduction}

Solid particle erosion is a very common phenomenon at material surfaces, which causes mass flaws in material surfaces due to the collision of material surfaces and solid particles [1, 2]. Therefore, erosion can significantly decrease the service life of industrial equipment. This phenomenon causes much inconvenience and even serious damage in our daily life and production, moreover, which leads to high economic losses every year. For instance, solid particle erosion is a frequent problem in oil and gas industry, solid particle erosion obviously reduces the service life of oil and gas pipeline, which results in increased equipment maintenance costs [3,

\footnotetext{
*Correspondence: niushichao@jlu.edu.cn; zwhan@jlu.edu.cn

${ }^{1}$ Key Laboratory of Bionic Engineering (Ministry of Education), Jilin

University, Changchun 130022, China

Full list of author information is available at the end of the article
}

4]. Solid particle erosion exists in hydropower field too, the erosion of solid particles in water can cause serious damage to the surface of hydraulic turbine blade, which is an important reason for efficiency and performance loss of hydropower plant [5, 6]. Fan is a typical ventilation in industrial production and erosion is a common phenomenon for it, erosion leads to a material loss of blade and a decrease of blade chord and effective camber that together take down the aerodynamic performance of fan $[7,8]$. In harsh working conditions, the hazard of solid particle erosion will become much worse. Generally, to overcome the problems caused by solid particle erosion, some engineering technologies have been used to increase the solid particle erosion resistance of materials. The traditional methods include oxidation, heat treatment, thermal spraying, and other technologies [9-11]. These solutions enhance the solid particle erosion resistance of materials by 
improving their mechanical properties and are widely used in industrial fields. Although studies of solid particle erosion resistance have been carried out for many years and obviously improved the service life of the aforementioned devices, these issues still not perfectly resolved. Moreover, in some fields with complex working conditions and high safety requirements, especially in military and aviation, there are still some challenges because of the properties of materials improved by traditional solutions are limited [12, 13]. In details, the service life of rotor and engine are greatly reduced due to the erosion of sand when a helicopter flies in desert area [12]. Engine blades of plane are seriously damaged owing to the erosion of volcanic ash when a plane sails in volcanic eruption area [13]. These phenomena can reduce the reliability and safety of apparatus, they are crucial to military and aviation fields. Therefore, exploring new solutions to solid particle erosion is necessary, which can offer new ideas to the erosion protection of the aforementioned devices, and may provide the possibility to solve the foresaid challenges.

After a long period of evolution, creatures in nature have evolved perfect abilities to adapt to their surrounding environments. Nature provides us with a large number of bio-inspired solutions for realizing splendid mechanical properties and mechanism elements to tackle specific engineering requirements, such as superhydrophobic surfaces with self-cleaning properties inspired by lotus leaves [14, 15], high-transmission and multiple antireflective surfaces inspired by the bimolecular 3D ultrafine hierarchical structure in butterfly wing scales $[16,17]$, and power efficient mechanoreceptors with flexible organic transistor circuits inspired by human skin [18]. These successful studies promote us to seek new insights from nature and to develop more bio-inspired functional materials. In nature, some typical creatures and organs provide new solutions to solid particle erosion (Figure 1). According
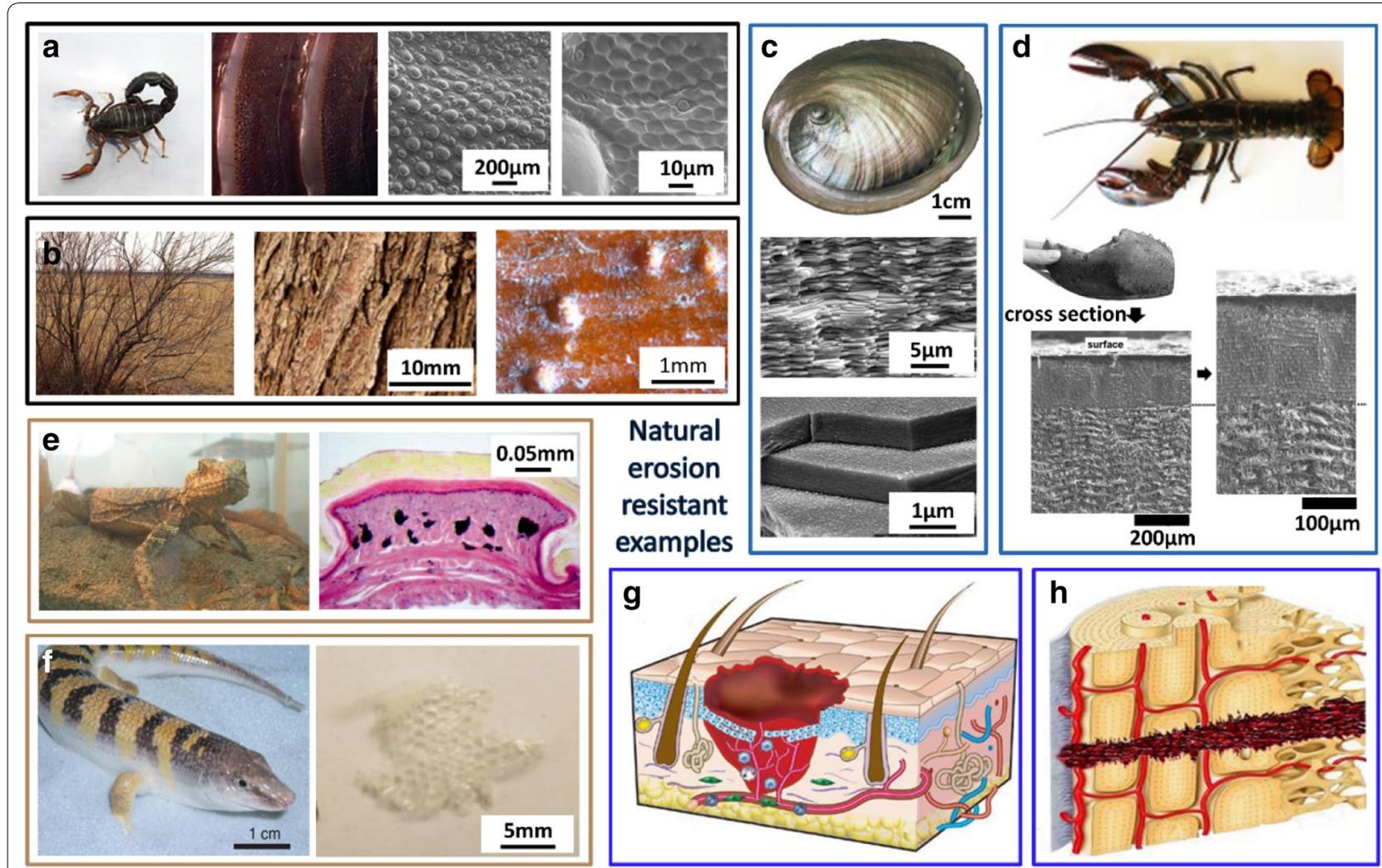

Figure 1 Different examples of natural resistance to solid particle erosion and the corresponding micro/nanostructures: (a) The armor of the desert scorpion (Androctonus australis) with special surface structures (curve, grooves, bumps and pits) has excellent erosion resistance [19]; (b) The tamarisk (Tamarix chinensis) can effectively resist sand erosion due to the special surface structures (curve, grooves and bumps) of the trunk surface [20]; (c) The layer-like nacre of a gastropod (Haliotis laevigata) assembled by aragonite platelets can reduce external impacts to protect the inner soft body [21]; (d) The lobster cuticle (Homarus americanus) with the twisted plywood structure exhibits excellent mechanical properties [22, 23]; (e) The desert lizard skin (Laudakin stoliczkana) can be used for preventing erosion from sand and have a hard layer and a soft layer in their buffered structure (Image of desert lizard provided by He Huang) [24]; (f) The sandfish skin (Scincus scincus) is durable [25, 26]; (g) Schematic illustration of the self-healing process of skin [27]; (h) Schematic illustration of the self-healing process of bone [28] 
to these new solutions, advanced bio-inspired functional materials can be designed for solid particle erosion resistance. For example, for protective purposes, the body surfaces of the scorpion and tamarisk, where a special surface structure is ubiquitous, can resist sand erosion very well $[19,20]$. This structure can improve the solid particle erosion resistance of natural creature surfaces by changing solid particle erosion factors. The nacre of a shell and the cuticle of the lobster also have a special internal structure [21-23]. The nacre is used for protecting internal soft tissue, and the cuticle is used for attacking prey because the special internal structure can improve the fracture toughness of the natural materials. The skins of the desert lizard and sandfish can resist wind-blown sand very well, mainly due to the buffering effect of the two-layer structure, which contains a hard layer and a soft layer [24-26]. For self-healing purposes, the internal vascular system of the skin or bone can transport healing substances to injury sites to repair the injury and prevent deterioration of the injury $[27,28]$. Therefore, by simulating natural materials with these special structures, novel and ingenious solutions to solid particle erosion can be found.

Several reports have been published on solid particle erosion resistance, which were mainly based on coatings, composite materials and solid particle erosion mechanisms [29-31]. However, to the best of our knowledge, a review on systematically introducing bionic solutions to solid particle solutions has not been presented. The traditional researches on erosion resistance to solid particle erosion often involve improving the mechanical properties, such as the hardness, strength and fracture toughness, by conventional processing technologies. The effectiveness of these solutions is limited. Therefore, we need to find new inspiration from nature. To this end, we summarize the recent progress in bio-inspired anti-solid particle erosion solutions. First, the basic theories of solid particle erosion resistance performance are briefly introduced, and the effect of the main factors that can affect the solid particle erosion resistance of materials is also noted. Next, by learning from nature, the solid particle erosion resistance mechanisms of eight natural examples are explained, and they are divided into four types. Afterwards, according to the different types of antisolid particle erosion solutions inspired by nature, the fabrication and anti-solid particle erosion effect of artificial anti-solid particle erosion materials are discussed. In addition, the current and promising applications of bio-inspired anti-solid particle erosion materials in different areas are also presented. Finally, the challenges and opportunities for bio-inspired anti-solid particle erosion materials are briefly addressed.

\section{Basic Theories and Main Influencing Factors of Solid Particle Erosion Resistance}

\subsection{Solid Particle Erosion Mechanisms}

When solid particles impact material surfaces, a material loss phenomenon occurs at the material surfaces due to the exchange of energy, and part of the kinetic energy of the solid particles is involved in surface material removal. This process is the root of the solid particle erosion phenomenon. The process of surface material removal depends on many parameters, such as the size, shape, impact velocity and impact angle of the solid particles, hardness of the surface material and solid particles, and fracture toughness of the surface material. Based on the energy exchange process, researchers explained the solid particle erosion mechanism of materials through different technical means. Because of the different damage mechanisms of surface materials, we often divide materials into ductile materials and brittle materials to more accurately explain the solid particle erosion phenomenon. Next, the solid particle erosion mechanisms of different materials are briefly introduced.

For ductile materials, many different solid particle erosion mechanisms have been proposed by different researchers. Finnie proposed a micro-cutting mechanism; he considered abrasive particles as cutting tools, and small craters could be created as the result of the impact of the particles [32]. This solid particle erosion mechanism explains the relationship between the erosion rate and impact angle and predicts that the maximum erosion rate occurs at a low impact angle. However, this mechanism is only applicable at low impact angles, and a large error appears when the impact angle is high, especially at $90^{\circ}$ [32]. Bitter explained solid particle erosion as a phenomenon combining deformation and cutting, and this mechanism can easily be used to obtain an erosion curve; however, specifying the appearance of solid particle erosion is difficult [33, 34]. Hutchings put forward a low cycle fatigue solid particle erosion theory for when the impact angle is $90^{\circ}$ [35]; he discussed the relationship between the phenomenon of solid particle erosion and the increment of plastic strain of surface material and thought that a critical plastic strain results in the removal of wear debris. Sundararajan found that the friction force between impact particles and the surface of the eroding material brings about deformation beyond the critical plastic strain and energy dissipation of the impact particles, regardless of normal or oblique impact, which is the main reason for solid particle erosion [36]. Bellman and Levy proposed a macroscopic solid particle erosion mechanism, and they thought that the removal of surface material can be described as a combination of forging and extrusion processes [37]. 
Particles hitting the material surface create shallow craters or platelet-like pieces during the process of solid particle erosion, and these pieces are knocked out by the subsequent impact particles. This mechanism can explain the solid particle erosion phenomenon of materials very well (Figure 2a) [31, 37, 38].

Compared with ductile materials, the solid particle erosion mechanism of brittle materials is easy to understand. Rather than plastic deformation, cracks occur on brittle material surfaces when solid particles impact the surfaces. Due to the continuous impact of solid particles, the cracks gradually expand, and surface material can be removed because these cracks divide the surface material into small scraps (Figure 2b) [32, 38-40]. Fundamentally, the formation and growth of cracks on the surfaces of brittle materials lead to the phenomenon of solid particle erosion [41, 42].

The above solid particle erosion mechanisms are widely accepted and used. In summary, in the solid particle erosion process of ductile and brittle materials, energy exchange occurs between the impact particles and material surfaces. The impact particles transfer part of their kinetic energy to the material surfaces, which causes damage to the material surfaces. For ductile materials, this energy causes plastic deformation or direct removal of surface material. In contrast, for britthe materials, this process brings about cracks, and with the growth of the cracks, surface material is eroded. In other words, solid particle erosion is the process of energy exchange and surface material removal owing to the energy from the impact particles. The above classical mechanisms have guiding significance for the research of the solid particle erosion process of engineering materials, although some engineering materials are not typically ductile or brittle materials.

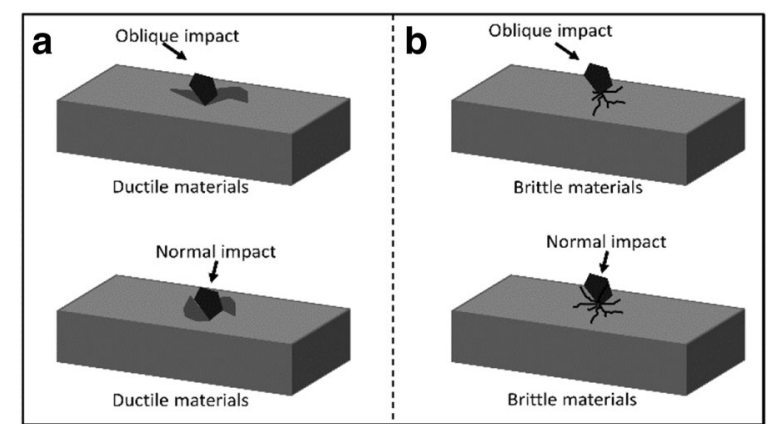

Figure 2 Schematic diagrams of the solid particle erosion process of ductile and brittle materials: (a) Ductile materials; (b) Brittle materials

\subsection{Main Factors for Assessing Solid Particle Erosion Resistance}

\subsubsection{Particle Properties}

The properties of solid particles, such as the shape, size, hardness, impact velocity and angle, have a significant influence on the process of solid particle erosion, and the influence of different factors is different. When solid particles hit material surfaces, angular particles are more likely to damage the material surfaces than spherical particles because angular particles can cut surface materials more easily and cause a stress concentration due to the presence of sharp corners. Hutchings found that angular particles mainly cause deformation as a result of cutting, and spherical particles cause relatively more furrow deformation [43]. Levy et al. [44] reported that the erosion rate caused by angular particles is four times that caused by spherical particles. Particle hardness also has an important relationship with the erosion rate. With the breakup and adherence of softer particles, the energy used to remove material decreases, which leads to a reduction in the erosion rate [31, 44]. Therefore, harder particles can easily damage material surfaces, and the erosion rate does not increase after the particle hardness reaches a certain value (Figure 3a) [31, 44]. Particle size is another parameter influencing the erosion rate of materials. As the particle size increases, the kinetic energy of particles becomes larger, which leads to an increase in the erosion rate, and larger particles intrude into surface materials more deeply than smaller particles $[45,46]$. However, the erosion rate almost does not increase when the particle size exceeds a certain value (Figure $3 b)[45,46]$. Particle velocity is another main factor of the erosion rate which is directly related to the kinetic energy, and a relationship is manifested between the erosion rate and particle velocity [32, 47, 48]. The kinetic energy of particles exponentially rises when the particle velocity linearly increases, which leads to more energy being used to damage surface material, and the erosion rate obviously increases (Figure 3c). Similarly, particle density has a close relationship with the weight of the impact particles which is an important indicator of kinetic energy, particle density also can affect erosion rate because particles with higher density have higher kinetic energy and create more impact force, high particle density, high erosion rate [44]. Because of the difference in the solid particle erosion mechanisms of ductile and brittle materials, different materials show different erosion curves as the particle impact angle changes [49-51]. For ductile materials, with increasing impact angle, the erosion rate first rises and then decreases after the impact angle reaches a certain value (Figure 3d) [49, 51]. For brittle materials, with 

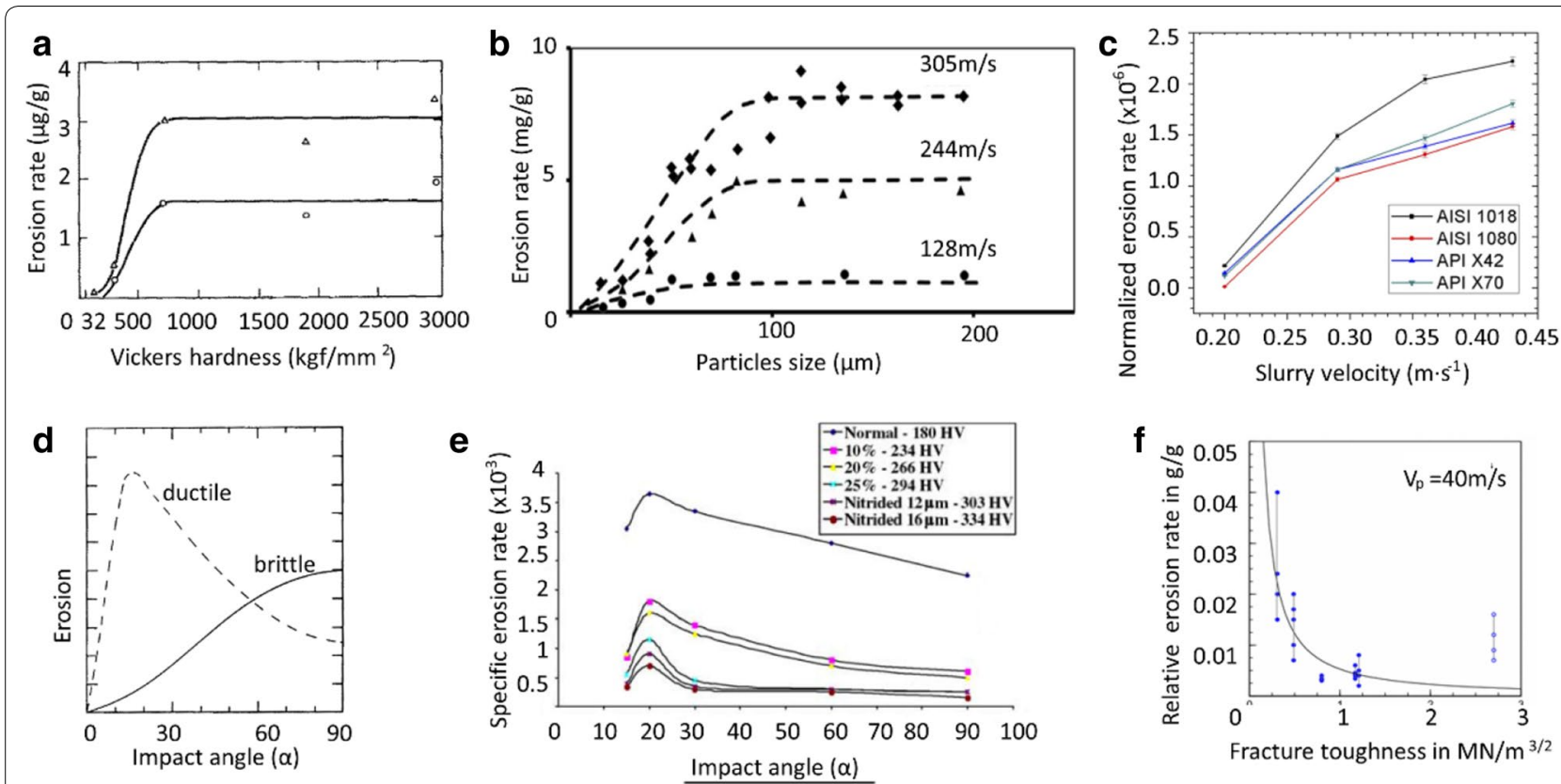

Figure 3 Schematic diagrams of the influence of different factors on the erosion rate: (a) Particle hardness (impact angles of $30^{\circ}$ and $90^{\circ}$ ) [44]; (b) Particle size (different impact velocities) [46]; (c) Impact velocity (different materials) [48]; (d) Impact angle (ductile and brittle materials) [49]; (e) Material hardness (different impact velocities) [52]; (f) Material fracture toughness [53]

increasing impact angle, the erosion rate continues to rise and reaches a maximum value at approximately $90^{\circ}$ (Figure 3d) [49, 50].

\subsubsection{Surface Material Properties}

The properties of the surface material, such as the hardness and fracture toughness, also have an important influence on the solid particle erosion process. Materials with a higher hardness are generally thought to exhibit a higher solid particle erosion resistance; for example, AISI316 steel with a higher hardness shows better solid particle erosion resistance when impacted by silica sand particles because a surface material with a high hardness can better resist plastic deformation (Figure 3e) [52]. Simultaneously, according to the solid particle erosion mechanisms of brittle materials, the fracture toughness of brittle materials is also associated with the erosion rate. With decreasing fracture toughness, the brittleness of materials increases, which leads to the propagation of cracks becoming easier and results in a high erosion rate of the materials (Figure 3f) [31, 53]. Erosion performance is a complex phenomenon, therefore, the evaluation of the erosion resistance of materials by a single factor is limited. In recent years, there are some studies about assessing wear and abrasion resistance of engineering and biological materials. Using mechanics models of contacting surfaces under both normal and tangential loads, the mechanistic frameworks for assessing wear and abrasion resistance of materials are presented [54, 55]. Moreover, under the guidance of the functions containing multiple material properties, such as hardness, fracture toughness and strength, the wear and abrasion resistance of various engineering and biological materials can be compared and evaluated, the material parameters contained in the functions are different under different mechanics models $[54,55]$. As an important branch of wear, the above described evaluation method provides a good reference for the evaluation of the erosion resistance of materials. It is more reasonable to consider the effects of various material properties on the erosion resistance. In comparison with existing parameter, a new parameter defining by various material properties, such as hardness, fracture toughness, can be used to precredit the erosion mechanism of materials at different operating conditions more accurately [56]. In summary, the enhancement of the hardness and fracture toughness of a surface material improves the solid particle erosion resistance of the material. Moreover, the microstructure of the surface material also affects the erosion rate because which is related to the hardness and fracture toughness of materials. In other words, materials with various microstructures have different resistance to the removal of materials, which determines their different erosion resistance [31].

In addition to the above factors, other factors can affect the erosion rate of materials too. For example, work 
hardening, fluid properties and ambient temperature. The influence of these factors can be explained in relation to the factors detailed above. The impact of solid particles on materials can cause work hardening which increases the hardness of materials and reduces the toughness of materials, these two factors are closely related to the erosion resistance of materials. The properties of fluid, such as the concentration and viscosity, also have a large influence on the dynamic performance of the impact particles to affect the phenomenon of erosion [57]. High concentration means that more solid particles erode materials, which results in higher erosion rate [57]. Fluid viscosity affects the trajectory of the solid particles in fluid, thereby affecting the phenomenon of erosion [57]. The change of ambient temperature brings out the change of the properties of materials and fluid, resulting in the change of the erosion rate $[31,57]$. Generally speaking, the solid particle erosion phenomenon is determined by a variety of factors, and these factors work together to affect the erosion rate of materials (Figure 4).

\section{Natural Solutions for Resisting Solid Particle Erosion}

As mentioned above, solid particle erosion is affected by many factors. In the design of engineering equipment for solid particle erosion resistance, the particle properties are not easy to control because they are related to the working environment of the engineering equipment. Therefore, changing the properties of the surface material is the main method to reduce erosion damage from solid particles. To find new solutions to improve the solid particle erosion resistance of materials, considering the mechanisms mentioned above, we look for inspiration from creatures that have excellent solid particle erosion

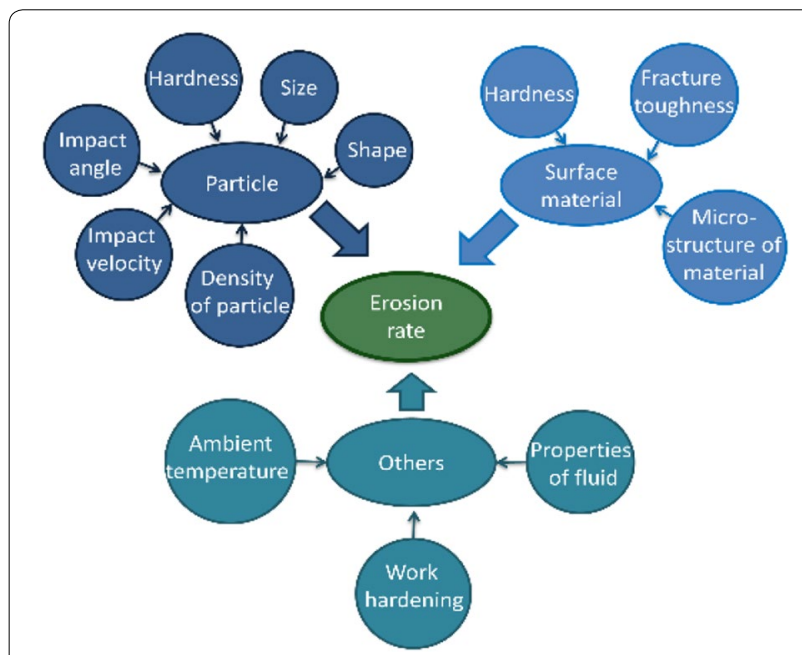

Figure 4 The main factors affecting the erosion rate of materials resistance. Commonly, we often first choose creatures from desert, semidesert and sand-beach environments, as these creatures have undergone long-term natural selection to adapt to the sand erosion environment; thus, they have excellent resistance to solid particle erosion. Many types of natural solutions to solid particle erosion that learn from nature can be found. After preliminary selection, the micro/nanostructure has a positive effect on the excellent mechanical properties of biomaterials. In this section, we summarize recent research progress in bio-inspired anti-solid particle erosion solutions and expound their solid particle erosion resistance mechanisms.

\subsection{Special Surface Structure}

To adapt to different living environments, a wide range of creatures have evolved various extraordinary structures on their body surface, such as scorpions and tamarisks living in desert or semidesert areas. These creatures are often eroded by sand and have evolved special antisolid particle erosion body surfaces. Many studies on the extraordinary structure of the special surfaces have been performed. This structure has a special influence on the trajectory of impact particles, thus changing key influencing factors of the erosion rate, including the velocity and impact angle of the particles, among others. The special surface structure can be divided into grooves, bumps, curve and pits (Figure 5). Next, we specifically explain the solid particle erosion resistance principles of these structures.

\subsubsection{Groove}

Grooves have been found on the body surfaces of several creatures that frequently suffer from solid particle erosion. For instance, the carapace of the scorpion is composed of several dorsal mesosoma segments, and adjacent segments are connected by an unsclerotized and flexible articular membrane, forming a groove structure (Figure 5ai) [58]. The tamarisk trunk surface suffers from long-term sand erosion, which causes the cells to divide faster, forming a groove structure on the surface (Figure 5aii), and the windward surface has better mechanical properties than the leeward side of the trunk [59]. The grooves observed in the carapace of the scorpion and body surface of the tamarisk can decrease the erosion rate by a similar strategy. The special flow pattern in groove structure significantly influences the solid particle erosion resistance of biomaterials. The rotating flow forms an air cushion in the groove structure, which changes the trajectory and velocity of solid impact particles (Figure 5aiii) [60-62]. On the one hand, the groove structure can enhance fluid turbulence, which changes the flow field around the surfaces of groove structure. 

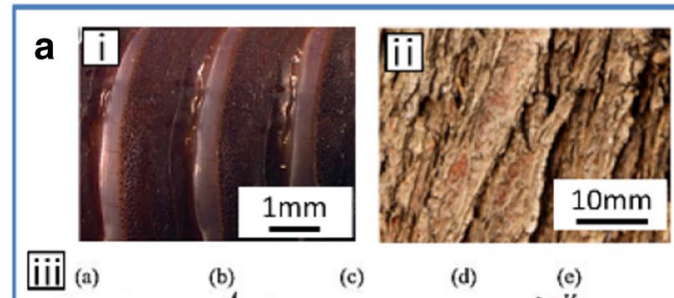

(b)

(c)

(d)

(c)

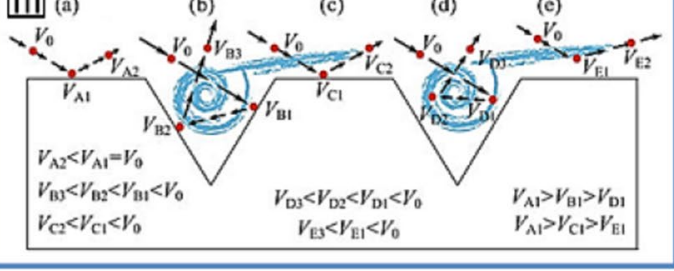

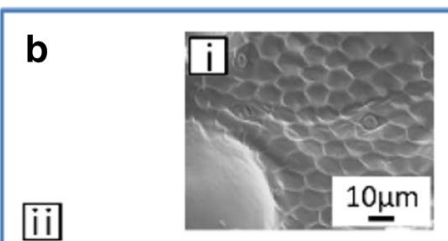
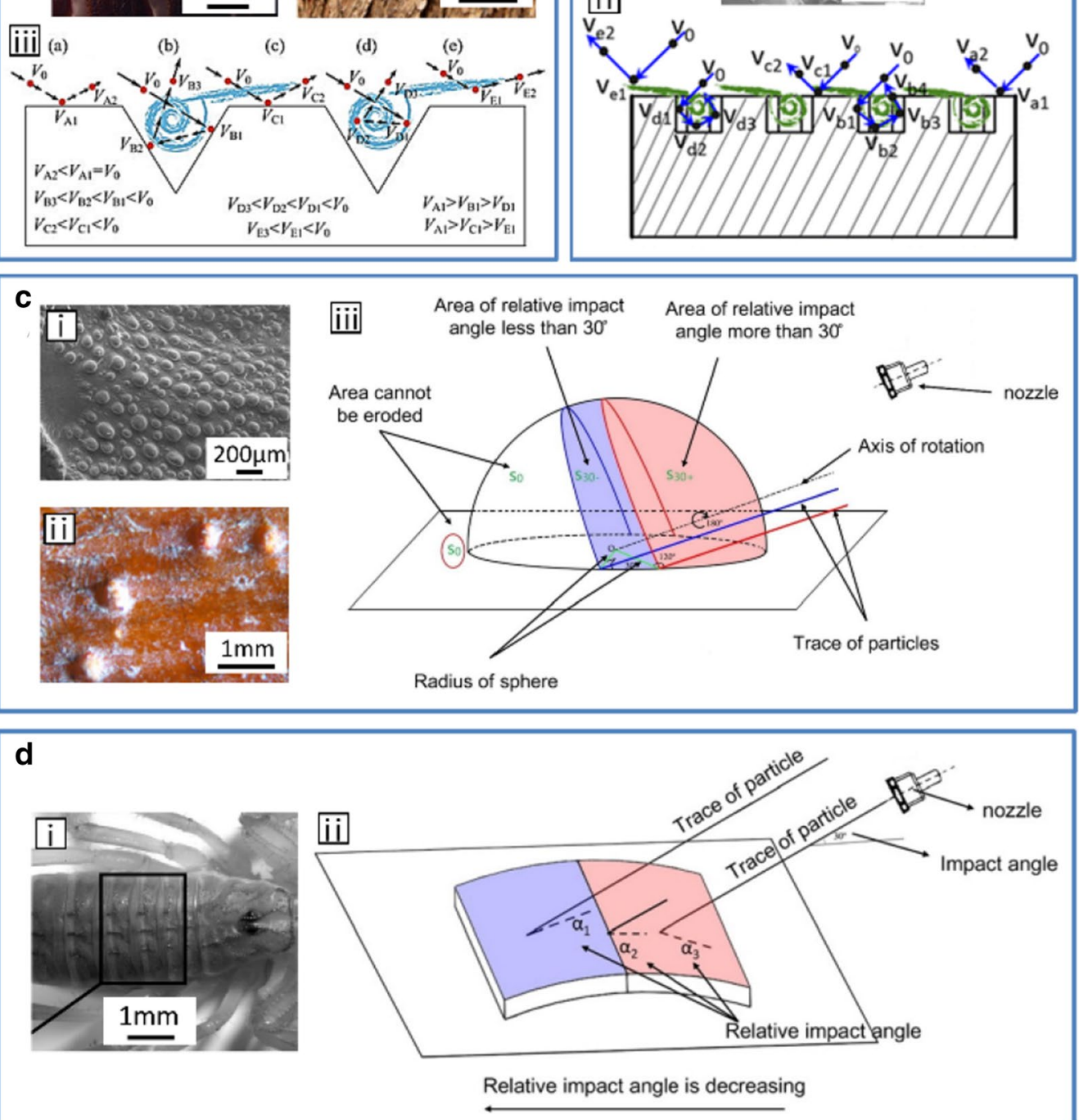

Figure 5 Special surface structures and their anti-solid particle erosion mechanisms: (a) (i) Grooves of the desert scorpion (Androctonus australis) [19], (ii) grooves of the tamarisk (Tamarix chinensis) [20], (iii) the anti-solid particle erosion mechanism of grooves (Androctonus australis) [20]; (b) (i) Pits of the desert scorpion (Androctonus australis) [19], (ii) the anti-solid particle erosion mechanism of pits [19]; (c) (i) Bumps of the desert scorpion [19], (ii) bumps of the tamarisk (Tamarix chinensis) [66], (iii) the anti-solid particle erosion mechanism of a bump [66]; (d) (i) Curve of the desert scorpion (Androctonus australis) [66], (ii) the anti-solid particle erosion mechanism of a curve [66]

Meanwhile, the motion pattern of the solid impact particles is subsequently changed, and the frequency of particles impacting the surfaces is decreased. On the other hand, the velocity of the solid impact particles in the two-phase flow is also decreased because of the detracting flow velocity. The rotating flow can absorb and diminish the collision energy of the solid impact particles, thus reducing the erosion rate of surface biomaterials. The effect of the groove structure on the erosion rate is different when the impact angle changes. The groove structure can decrease the erosion rate at impact angles ranging from $20^{\circ}$ to $60^{\circ}$. When the impact angle is outside of this angle, a smooth surface shows better solid particle erosion resistance [63]. Similarly, the ribs of a shell, which 
are perpendicular to flowing water or sand in the middle part, can not only alter the trace of the solid impact particles but also change the stress distribution produced by the solid impact particle flow to improve the solid particle erosion resistance similar to grooves [64].

\subsubsection{Pit}

Moreover, pits have been found in the armor of the scorpion (Figure 5bi). Pit structure can form rotational flow when solid particles are smaller than pit [19]. Which affects the motion of the solid impact particles, in particular, the impact velocity and the number of the solid particles impinging on biomaterial surfaces are both decrease (Figure 5bii) [19]. The velocity and kinetic energy exhibit an exponential relationship, a decrease in the kinetic energy of the solid impact particles can lower the erosion rate. In addition, the reduce of the solid particles number impinging on the biomaterial surfaces mean less energy are used to damage the biomaterial surfaces, which indicates lower erosion rate. Moreover, when the solid particles are bigger than pits, the solid particles could not be blown inside the hexagonal pit interior. Rotational flow could reduce the normal velocity of the solid particles, which is advantageous for reducing the erosion rate [19].

\subsubsection{Bump}

Additionally, other structures that can reduce the erosion rate have also been found. Bumps existing in the carapace of the scorpion and the trunk surface of the tamarisk also play an important role in the anti-solid particle erosion process $[20,65]$. Due to the stimulation of sand, the proliferation and differentiation of tissue cells on the trunk surface of the tamarisk are promoted, resulting in a bump structure after a long time (Figure 5ci) [59], and the formation process of the bumps of a scorpion is similar (Figure 5 cii). The bump structure can change the relative impact angle of solid impact particles. When a solid particle collides with the bump surface, the relative impact angle is not equivalent to the angle between the trajectory of the solid particle and the horizontal plane; the relative impact angle is the angle between the trajectory of the solid particle and the tangent of the bump structure at the collision point. When the maximum erosion angle of the material is $30^{\circ}$, the bump structure is divided into three areas, $\mathrm{S}_{30+}, \mathrm{S}_{30-}$ and $\mathrm{S}_{0}$ (Figure 5ciii) [66]. Regardless of the impact angle of the solid impact particles, only at the intersection of $\mathrm{S}_{30+}$ and $\mathrm{S}_{30-}$ (the red arc) is the relative impact angle equivalent to the angle between the trajectory of the solid particle and the horizontal plane [66]. In addition, regarding the areas of $\mathrm{S}_{30+}$ and $\mathrm{S}_{30-}$, the relative impact angle is larger than the angle between the trajectory of the solid particle and the horizontal plane in the area of $\mathrm{S}_{30+}$, whereas the relative impact angle is smaller than the angle between the trajectory of the solid particle and the horizontal plane in the area of $S_{30-}$ [66]. The impact angle is obviously an influencing factor that affects the process of solid particle erosion, and a change in the impact angle from when the impact angle is the maximum erosion angle reduces the erosion rate. The bump structure can improve the solid particle erosion resistance performance of surface biomaterials by changing the relative impact angle [66]. Moreover, the $S_{0}$ area (a small portion of the bump structure and the planar portion near the bump) is not eroded by solid particles, which also greatly reduces the total erosion rate of the surface biomaterial [66]. Geometrically, the smaller the impact angle is, the larger the area that is not impacted by the particles, and the lower the erosion rate of the material.

\subsubsection{Curve}

In the end, curve has been observed on the body surface of the scorpion (Figure 5di). This structure also greatly improves the anti-solid particle erosion function of the body surface of the scorpion. When solid particles collide with the surface of the curved structure, the relative impact angle is often different from the angle between the trajectory of the solid particles and the horizontal plane of the surface (Figure 5dii) [66]. Similar to the principle of the bump structure, the curved structure reduces the erosion rate by changing the relative impact angle [66].

In general, compared with the smooth structure, these structures (groove, bump, pit and curve) exhibit better solid particle erosion resistance. Although a single structure can significantly improve the solid particle erosion resistance of biomaterials, the combination of different structures can work better; this phenomenon has been verified in the body surfaces of scorpion and tamarisk because they have a variety of surface structures $[19,65$, 66]. For example, the body surface of the tamarisk has groove, bump and curve structure, and they work synergistically to improve the solid particle erosion resistance [20]. The armor of the desert scorpion has excellent solid particle erosion resistance because of the comprehensive role of groove, bump, curve and pit structure [19, 66]. The special surface structure is generally accepted to mainly improve the solid particle erosion resistance of biomaterials by changing the velocity and trajectory of solid impact particles and reducing the eroded area of the biomaterial surface.

\subsection{Extraordinary Inner Structure}

In addition to the impact velocity and angle of solid particles, the solid particle erosion resistance is also affected by the hardness and fracture toughness of biomaterials. 
During the process of solid particle erosion, high hardness and fracture toughness can reduce plastic deformation and the crack generation rate to improve the solid particle erosion resistance. Generally, the hardness and fracture toughness of common engineering materials are opposite to each other, but they are both important factors affecting the ability to resist solid particle erosion. Therefore, it is urgently need to find a new way to solve this problem. In nature, some biomaterials with both high hardness and excellent fracture toughness have been found, which provide us with new ideas for solving solid particle erosion. To understand the special mechanism of these biomaterials, in recent years, many studies have focused on their complex internal architectures [67-69]. We can design new materials with excellent mechanical properties by mimicking their strategies. In this review, we mainly discuss two types of biomaterials, the nacre of gastropods and the cuticle of the lobster. Because gastropods mainly live on the beach and lobsters are also widely distributed in the offshore sea and on the shore, they are inevitably subject to the erosion of sand, as they live in such environments. Therefore, the study of their mechanical properties has important engineering significance for the research of anti-solid particle erosion. According to the different arrangements of their internal structure, we divide their structure into the following types for discussion.

\subsubsection{Brick and Mortar Structure}

The brick and mortar structure is found in nacre and plays a critical role in the impressive mechanical performance of nacre [70, 71]. The nacre of gastropods is used to protect against predator attacks and erosion from seawater sediment (Figure 6a). Nacre is composed of aragonite (at least $95 \%$ by volume) and organic polymer (at most $5 \%$ by volume) [72]. Aragonite is a brittle material that is highly prone to crack generation and expansion, and aragonite has terrible fracture toughness. Therefore, aragonite is extremely vulnerable to damage when impacted by foreign objects. However, with the addition of softer material (organic polymer), mortar is formed between brittle slices of aragonite (approximately $0.5 \mu \mathrm{m}$ thick), aragonite and the organic polymer together form a brick and mortar structure (Figure 6b, c) $[73,74]$. In the brick and mortar structure, aragonite is the brick and the organic polymer is the mortar [75]. Stress redistribution occurs in the areas of stress concentration as a result of sufficient inelastic deformation of the softer material [68]. We mainly discuss the mechanical behavior of the fracture resistance of nacre during the expansion process of cracks. The fracture resistance is attributable to the special brick and mortar structure. The principal toughening mechanisms of nacre are crack deflection along the tablets, crack bridging, and sliding of the microscopic tablets. As shown in Figure 6d, during the process of crack spreading, reinforcing "bridges" are formed across the faces of the cracks. At the same time, owing to the stress concentration, high stress zones are formed near the cracks, which are divided into the "frontal zone" and "wake zone" [76]. In these zones, aragonite tablets slide between each other because of the shear stress. Therefore, the energy of fracture is greatly consumed in these zones, which prevents further growth of cracks, as the expansion of the cracks requires energy [76]. As a special construction, a particular deformation behavior appears in nacre, and its fracture toughness
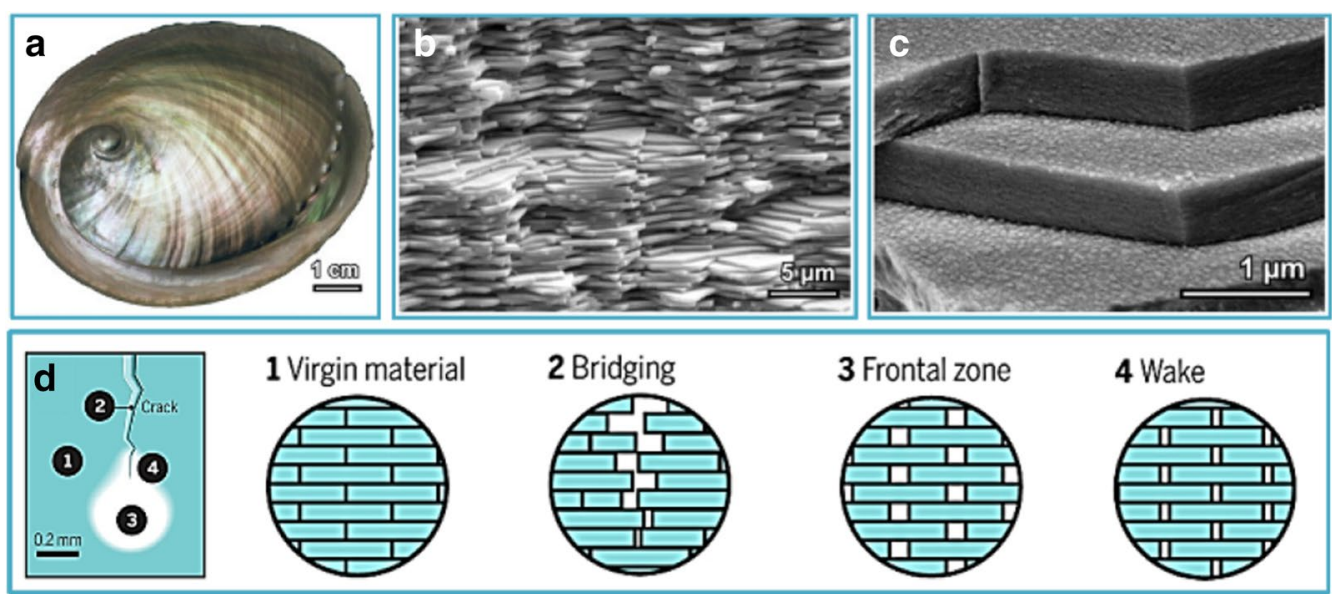

Figure 6 (a) The inner iridescent region of a gastropod (Haliotis laevigata) [21]; (b) The fractured cross section of the nacreous layer obtained by scanning electron microscopy (SEM) [21]; (c) A close-up view on the platelets obtained by high-magnification SEM [21]; (d) Schematic diagram of the fracture resistance of brick and mortar structure [76] 
(approximately $1.5 \mathrm{~kJ} / \mathrm{m}^{2}$ ) is 3000 times that of a pure aragonite single crystal (approximately $0.001 \mathrm{~kJ} / \mathrm{m}^{2}$ ) [73]. Moreover, there is still controversy about the mechanisms of the restrain sliding of aragonite tablets. For example, breakage of mineral bridges: mineral bridge nanostructure is observed and measured in organic matrix layers, compare with aragonite layers, organic matrix layers are weak interfaces, mineral bridge nanostructure can strengthen the weak interfaces, resulting in the interfaces more suitable for propagation [77]. Inelastic shearing of nano-asperities: there are nano-asperities on the surface of aragonite tablets, the matched asperities first climb over each other until they are juxtaposed, then the tablets slip over the peaks of asperity in "steady-state" [78]. Visco-plastic deformation of organic material: there is a modular fibre between adjacent aragonite tablets, and sliding causes the fibre to be stretched and eventually destroyed. In the process of the fibre failure, multiple domains are sequentially broken, and the energy stored in the fibre is transferred as heat [79]. These mechanisms all believe that restrain sliding will increase the energy dissipation during the process of fracture, thereby improving the toughness of material. In general, when solid particles hit the biomaterial surface, because the main body is a brittle material, microcracks are first formed on the biomaterial surface. However, due to the above theories, a complex internal toughening process of the biomaterial occurs. This phenomenon can effectively reduce the erosion damage of solid particles to improve the solid particle erosion resistance of biomaterials.

\subsubsection{Twisted Plywood Structure}

The twisted plywood structure can be observed in some biomaterials, such as lobster cuticle [80, 81], stomatopod dactyl club [82], beetle exocuticle [83] and fish scales [84]. These biomaterials exhibit excellent mechanical properties that help the creatures resist predator attack and other impact damage. Lobster often live in the offshore area and on the beach, and the cuticle of the lobster can effectively resist the impact of a foreign object. We take the cuticle of the lobster as a typical case to analyze the characteristics of the twisted plywood structure. The cuticle of the lobster consists of the procuticle and underlying epidermal tissue, and the procuticle is made up of the exocuticle and endocuticle. The endocuticle is the hardest and stiffest tissue of the cuticle of the lobster. Figure $7 \mathrm{a}, \mathrm{b}$ show the special structure of the endocuticle, which is formed by the multilayer twisted plywood structure [85-87]. Many twisted plywood structures constitute the multilayer structure inside the endocuticle. The twisted plywood structure is formed by chitin-protein fibers helicoidally arranged in space, cuticle proteins and microscopic biominerals $[23,85]$. The plane of the cuticle exhibits a honeycomb-like structure with elliptic openings as the result of mineralization [85]. The chitin-protein fibers are assembled from clustered nanofibrils wrapped with proteins, and they are distributed among a mineralized-protein matrix [85]. Furthermore, the clustered nanofibrils are formed by $\alpha$-chitin chains [23]. Fundamentally speaking, at the molecular level, the nanofibril is $\mathrm{N}$-acetyl-glucosamine [85]. Figure 7c shows the elastic behavior of different hierarchical structural units of the lobster cuticle obtained with different simulation methods. The anisotropy of the mineralized chitin-protein nanofibril is 1.75 , but it decreases to 1.4 for the twisted plywood structure [85]. This result shows that the twisted plywood structure can improve the anisotropy of the biomaterial by twisting the fibrillar planes to improve the mechanical properties of the biomaterial [85]. Additionally, the plywood structure of biomaterials can prevent the propagation of cracks and dissipate a great deal of energy during the impact process, which are beneficial for improving the solid particle erosion resistance of biomaterials [85]. Other discussions about the twisted plywood structure of other biomaterials have been presented too, it is believed that this structure leads to enhanced damage tolerance and energy absorption of biomaterials due to the orderly arrangement of fibers, fibrils, or reinforcements [82-84, 87]. As the mechanical properties of biomaterials improve, the solid particle erosion resistance is improved.

In general, regardless of the brick and mortar structure or the twisted plywood structure, during the fracture process of biomaterials, the special arrangement of these internal structures improves the fracture toughness of the biomaterials. The fracture toughness is an important factor affecting the solid particle erosion resistance of materials. In particular, for brittle materials (e.g., ceramics), a high fracture toughness means that the probability of scrap falling off the material surfaces is lower during the process of solid particle erosion. For ductile materials, the energy dissipation reduces the stress concentration and plastic deformation on the surfaces, achieving the purpose of improving the solid particle erosion resistance of materials.

\subsection{Buffered Structure}

Many types of buffered structures exist in nature, and when biomaterials are impacted by foreign objects, buffered structures can absorb part of the impact energy, reduce stress concentration and improve the damage resistance of biomaterials. A buffered structure is versatile, and we mainly discuss its anti-solid particle erosion feature according to two typical creatures. After thousands of years of evolution, desert lizards have perfect abilities to adapt to sandy environments. In particular, 


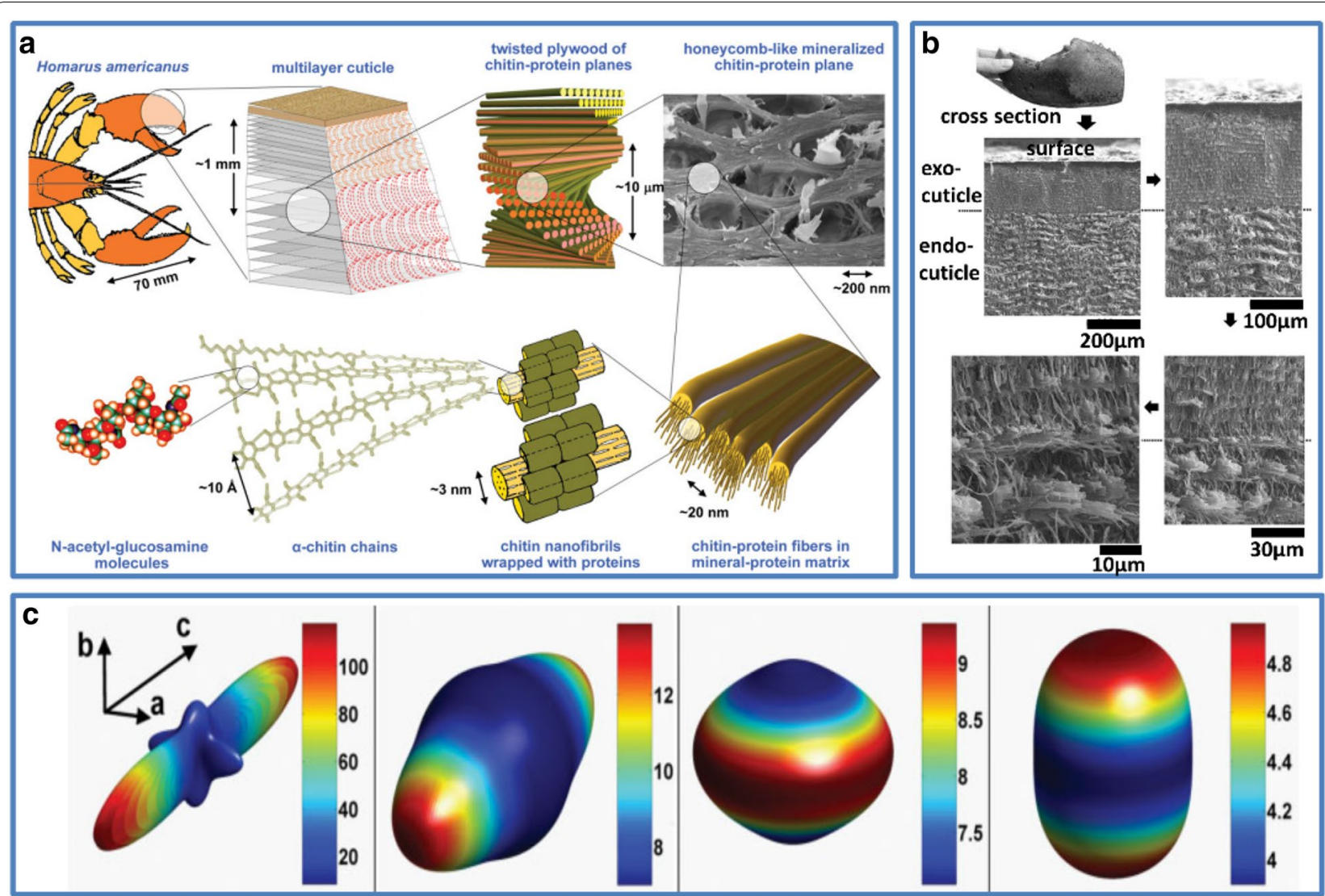

Figure 7 (a) The twisted plywood structure of the lobster cuticle (Homarus americanus) [85]; (b) SEM micrographs of the fractured surfaces of the lobster cuticle at increased resolution [23]; (c) 3D maps of the Young's modulus for different hierarchical structure units (a-chitin chains, chitinprotein nanofibrils in a planar array, twisted plywood stack of chitin-protein planes without pore canals, and twisted plywood stack of chitinprotein planes with pore canals) of the lobster cuticle obtained with different simulation methods [85]

the sandfish (a small desert lizard) can move a significant distance in sand, similar to a fish swimming in water, and the skin of the sandfish is durable in this process $[25,88$, 89].

Desert lizard have excellent resistance to sand erosion, as they live in a sandy environment. The skin of the desert lizard is made up of many individual scales, and the scales are interconnected but do not overlap [90]. Each single scale contains two parts (Figure 8aii): a hard shell (cuticle) and a soft core (dermis and subcutis) [24, 90]. When sand impacts the skin of the desert lizard, the hard shell can reduce elastic deformation, and the soft core can absorb part of the kinetic energy of the sand particles. In addition, buffered structure also can cut down stress disturbance base on the theory of stress wave propagation in solid, which can prevent the failure of materials [91]. Compared to single layer materials, this structure effectively improves the solid particle erosion resistance of the skin $[24,90]$. The sandfish is another typical example of a buffered structure; it can run several meters in sand when avoiding natural enemies, and the speed of the sandfish reaches $30 \mathrm{~cm} / \mathrm{s}$ [26]. Surprisingly, the skin of the sandfish shows better resistance to a blast of sand. Further research indicated that the scales of the sandfish can effectively resist normal loads but cannot withstand long scratching times compared with most engineering materials, especially from the microscopic point of view; the scales of the sandfish do not exhibit excellent frictional behavior [26]. Therefore, we can speculate that the scale is not the main reason for the sandfish's ability to swim in sand. On the one hand, the dynamics of subsurface locomotion of the sandfish are very mesmerizing; sand locally behaves as a viscous fluid instead of a solid material, which leads to a significant decrease in the kinetic energy of impacting sand (Figure 8b) [25, 88, 89]. On the other hand, the sandfish also has soft tissue under its skin, and the soft tissue can further reduce the impact kinetic energy of sand. The erosion rate naturally becomes low with the reduction of the impact energy.

In summary, Figure 8c shows the principle of the buffered structure. The soft layer can absorb part of the kinetic energy of the impact particle, and the thickness 

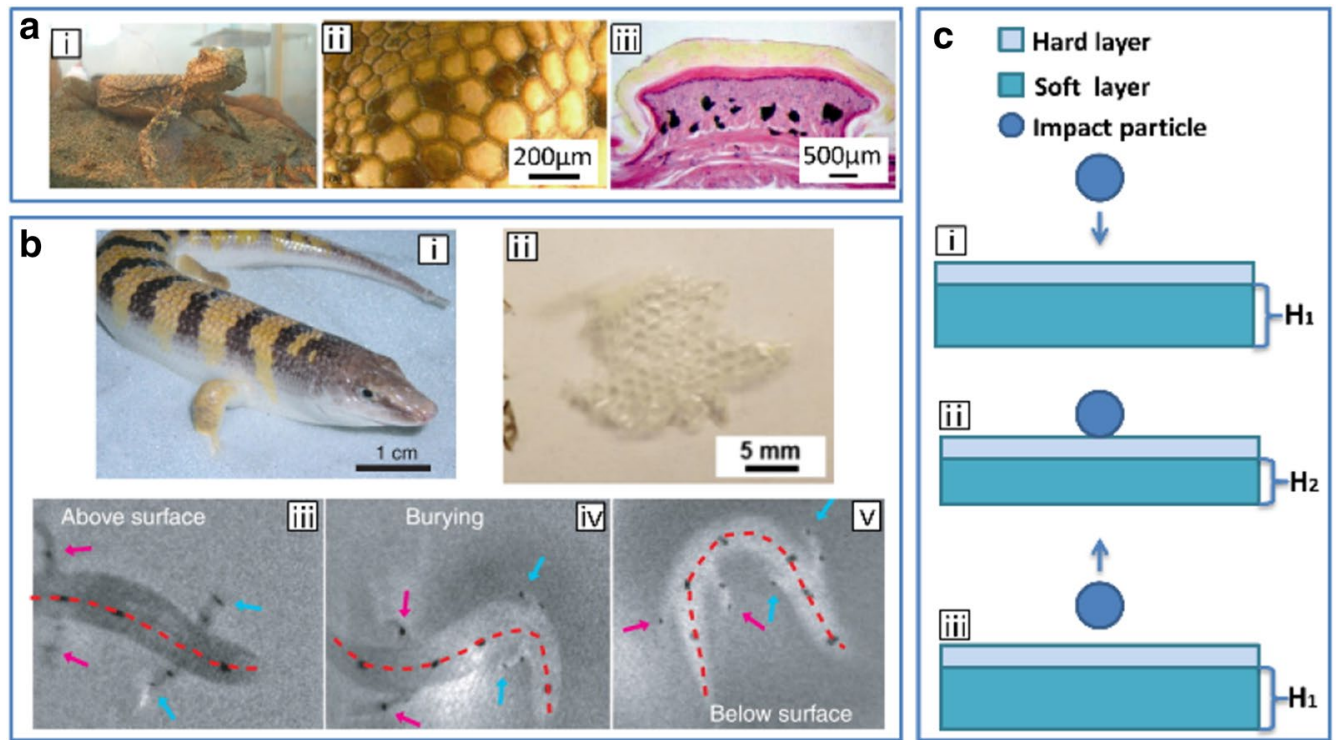

Figure 8 (a) The buffered structure of a desert lizard (Laudakin stoliczkana): (i) desert lizard (Provided by He Huang), (ii) a microscopic image of the scales of desert lizard [24], (iii) a section image of a single scale of desert lizard [24]; (b) Scales and dynamics of the sandfish (Scincus scincus): (i) sandfish [25], (ii) scales of the sandfish [26], (iii) X-ray image of the sandfish when moving on the surface [25], (iv) X-ray image of the sandfish when moving subsurface but its limbs are not buried in sand [25], (v) X-ray image of the sandfish when moving subsurface and all its body is buried in sand [25]; (c) A schematic diagram of the buffered structure: (i) an impact particle does not contact with the surface of the multilayer material, (ii) an impact particle collides with the multilayer material, (iii) an impact particle leaves the surface of the multilayer material, $\mathrm{H}$ is the thickness of the soft layer, and $\mathrm{H}_{1}$ is greater than $\mathrm{H}_{2}$

of the soft layer is changed. The hard layer further protects the material surface, with elastic deformation and restraint of crack formation and expansion. In nature, a soft layer beneath a hard layer is a common phenomenon. This structure is a typical buffered structure. Although little literature links the buffered structure to the solid particle erosion resistance of materials, we are sure that the buffered structure has a positive effect on the solid particle erosion resistance because of its excellent energy consumption capability.

\subsection{Self-healing Structure}

In addition to the above solutions to improve the erosion rate of materials, by learning from nature, another solution that has great potential to solve solid particle erosion of material surfaces can be found. In nature, some biomaterials have the ability of repairing themselves, and we often call this ability self-healing [92-95]. This selfhealing property of biomaterials can improve the damage resistance of the biomaterials.

Many examples of self-healing can be found in nature, such as self-healing of skin and bone $[27,92,93]$. These self-healing types have a common feature in the processes of self-healing, that transport of healing substances to damaged sites is necessary, thereby achieving the purpose of self-healing through the chemical action of the healing substances $[27,92,93]$. With the appearance of damage, such as skin abrasion and bone fracture, healing substances are transported to the damaged sites by the vascular capillary network in skin or bone (Figure 9) $[27,28,92,96]$. Under the action of these healing substances, the complex healing phenomenon occurs as healing substances continue to reach the designated sites, tissue continues to regenerate, and skin and bone complete the process of self-healing. In this special process, healing substances and their transportation are both key factors $[27,96]$. Research on healing substances is not the focus of this review because they mainly involve chemical behavior. This review mainly discusses the function of the internal damage-resistant structure of biomaterials. The premise of the repair process is that healing substances can reach the damaged sites; otherwise, skin or bone repair is not possible. In addition, in the process of selfhealing, the repair of tissue can also prevent the expansion of damage and improve damage resistance. The vascular capillary network is the structure for transporting healing substances, which are widely present in skin and bone. The vascular capillaries can deliver healing substances to the injury sites through internal channels after injury has occurred. Under the effect of healing substances, biomaterials can partially restore the mechanical properties and prevent further damage. Compared with 

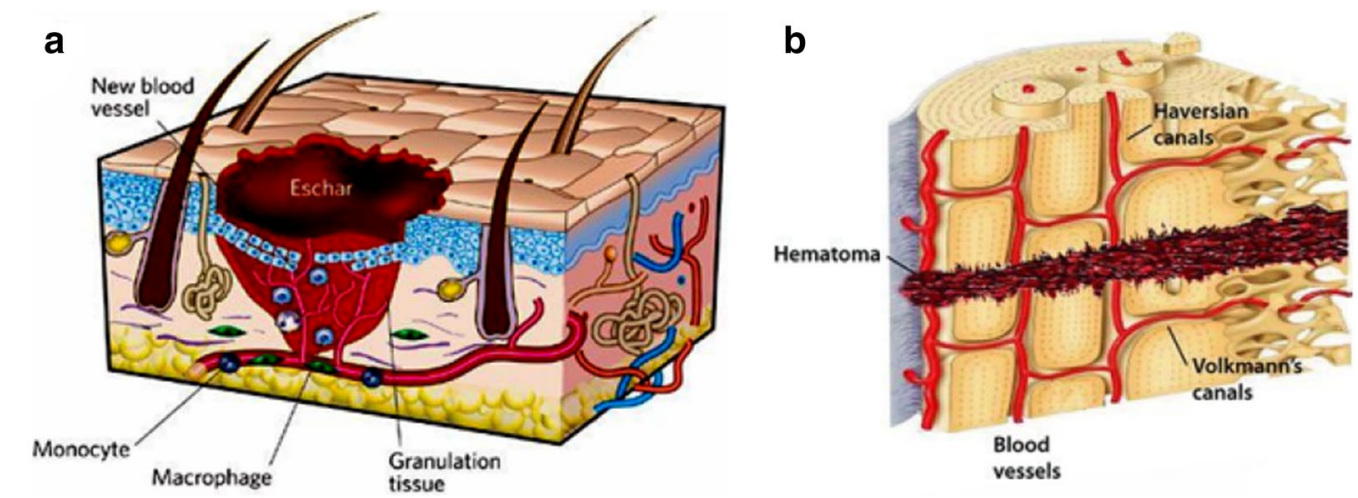

Figure 9 (a) A cartoon of the formation of new skin tissue [27]; (b) A schematic diagram of the self-healing of a bone injury [28]

the other solutions, the self-healing structure has good repair ability and saves maintenance time.

\section{Bio-inspired Anti-solid Particle Erosion Materials}

According to the several special structures described above, the corresponding anti-solid particle erosion solutions are summarized. Moreover, corresponding bioinspired materials are fabricated under the guidance of different solutions. The bio-inspired materials can also be classified into four categories based on the anti-solid particle erosion mechanisms: bio-inspired anti-solid particle erosion materials with special surface structures, extraordinary inner structures, buffered structure and self-healing structures. Next, the progress in these bioinspired anti-solid particle erosion materials in recent years is discussed.

\subsection{Bio-inspired Anti-solid Particle Erosion Materials with Special Surface Structures}

The special structure on material surfaces has a conspicuous influence on the velocity and trajectory of solid particles. In recent years, bio-inspired materials with different surface structures have been manufactured by various methods (Figure 10). The additive manufacturing technique is the most common method for fabricating bio-inspired materials with complex surface structures due to its high precision and versatility. In the process of additive manufacturing, acrylonitrile butadiene styrene and steel are commonly used materials $[19,65,66]$. Other techniques have also been used to manufacture relatively simple surface structures, such as laser techniques and machining $[60,61,97]$.

Imitating the grooves of the scorpion and tamarisk, bionic samples with different sizes of grooves were fabricated. First, the grooves were produced by a wire cut electric discharge digital control machine on the surface of AA 6061 samples. The cross section of the grooves was an equilateral triangle, and the surfaces of the samples were carefully polished by $\mathrm{SiC}$ emery paper [60]. Erosion wear tests showed that the anti-solid particle erosion properties of V-groove samples increased by approximately $57.4 \%$ [60]. Further, to verify the effect of different shape grooves on the solid particle erosion resistance of samples, three different shape grooves were fabricated on the surfaces of samples, and the matrix material of the samples was steel-45 (Figure 10a) [61]. The $\mathrm{V}$-shaped groove samples showed the best solid particle erosion resistance compared with the smooth samples, with an improvement in the solid particle erosion resistance of approximately 26\% (Figure 11a) [61]. Pit bionic units were processed by a YAG laser in the surfaces of samples (Figure 10b). The pits affected the solid particle erosion resistance, and the arrangement of these pits also affected the solid particle erosion rate of the samples (Figure 11b) [97]. Furthermore, some studies on coupled bionic samples (Figure 10c, d), which were all processed by $3 \mathrm{D}$ printing technology, were performed, and the matrix material of the samples was stainless steel $[19,66]$. Bump and curve can obviously significantly improve the solid particle erosion resistance of bionic samples when only one factor is considered (Figure 11c, d) $[19,66]$. The bionic samples with coupled structures exhibited better solid particle erosion resistance than the samples with a single structure (Figure 11e), as coupled structures are more similar to the body surface features of the scorpion and tamarisk (Figure 10c, d) $[19,66]$.

Most of the above tests were carried out when the erosion angle was $30^{\circ}$. However, the influence of the bionic surface structure on the erosion rate is different at different erosion angles. For example, grooves reduce the erosion rate only at impact angles ranging from $20^{\circ}$ to $60^{\circ}$ (Figure 11f) [63]. If the impact angle exceeds a certain range, then the erosion rate will dramatically increase. When the impact angle of particles relative to 

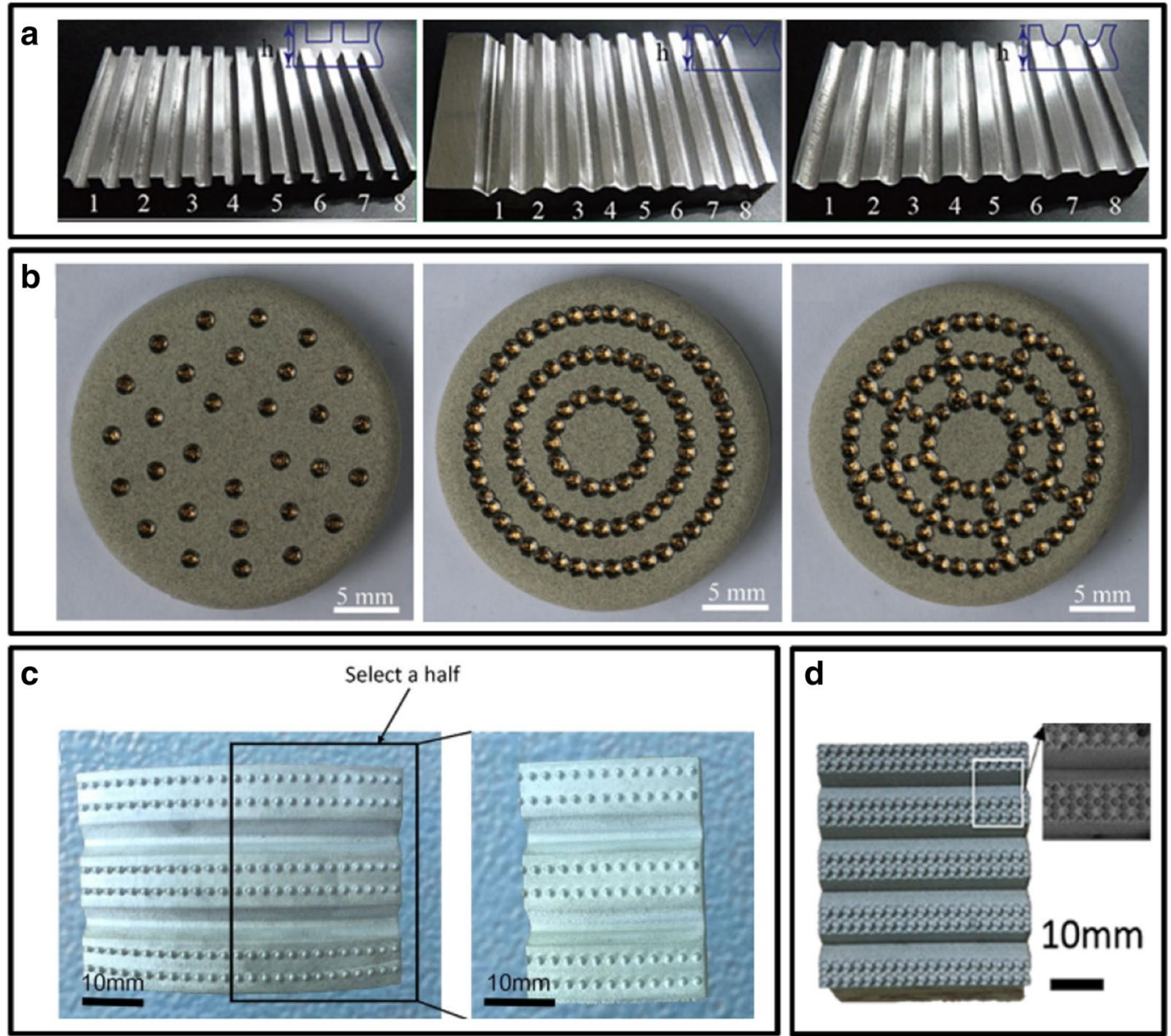

Figure 10 (a) Grooves with different shapes (square, U-shaped, and V-shaped), the material is steel-45 [61]; (b) Different arrangements of pits [97]; (c) A composite structure containing grooves, bumps and curve [66]; (d) A composite structure containing grooves, bumps and pits [19]

the surfaces of samples is outside the range of $20^{\circ}$ to $60^{\circ}$, the relative impact angle of particles on the surface of a groove exactly falls in the angle range where the erosion rate of materials is the largest [63]. Similarly, the other surface structures can also change the relative impact angle of particles on the surfaces of the structures, and the type and feature size of the structure affect the impact angle and even the velocity of particles. In addition, bump and curve can both reduce the erosion area of material surfaces to reduce the erosion rate, and the feature sizes of bump and curve have a close relation with the erosion area. The relative impact angle of particles, the impact velocity of particles and the erosion area of the surface all affect the erosion rate of materials. Thus, different surface structures obviously exhibit different solid particle erosion resistances. Furthermore, among the four characteristic structures, the groove structure has the best solid particle erosion resistance. Moreover, composite structures show better performance, and the combination of different structures also has a significant effect on the erosion rate of materials. However, compared with simple structures, the preparation of composite structures is relatively complex. Although the surface structure has an obvious effect on improving the solid particle erosion resistance of the materials, the function of the surface structure has certain limitations. For example, these structures do not work well at all erosion angles. A reasonable match between the size of the structure and the size of the component is also very important to achieve the best economic benefit. In the actual application process, different structures or their composite structure need to be chosen according to the actual situation.

\subsection{Bio-inspired Anti-solid Particle Erosion Materials with Extraordinary Inner Structures}

Due to the existence of the extraordinary inner structure, the mechanical properties of nacre and lobster's cuticle 


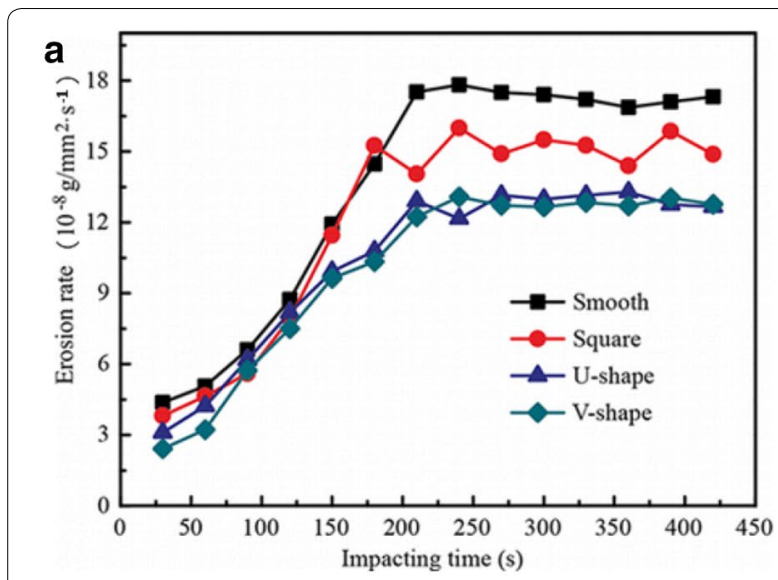

C
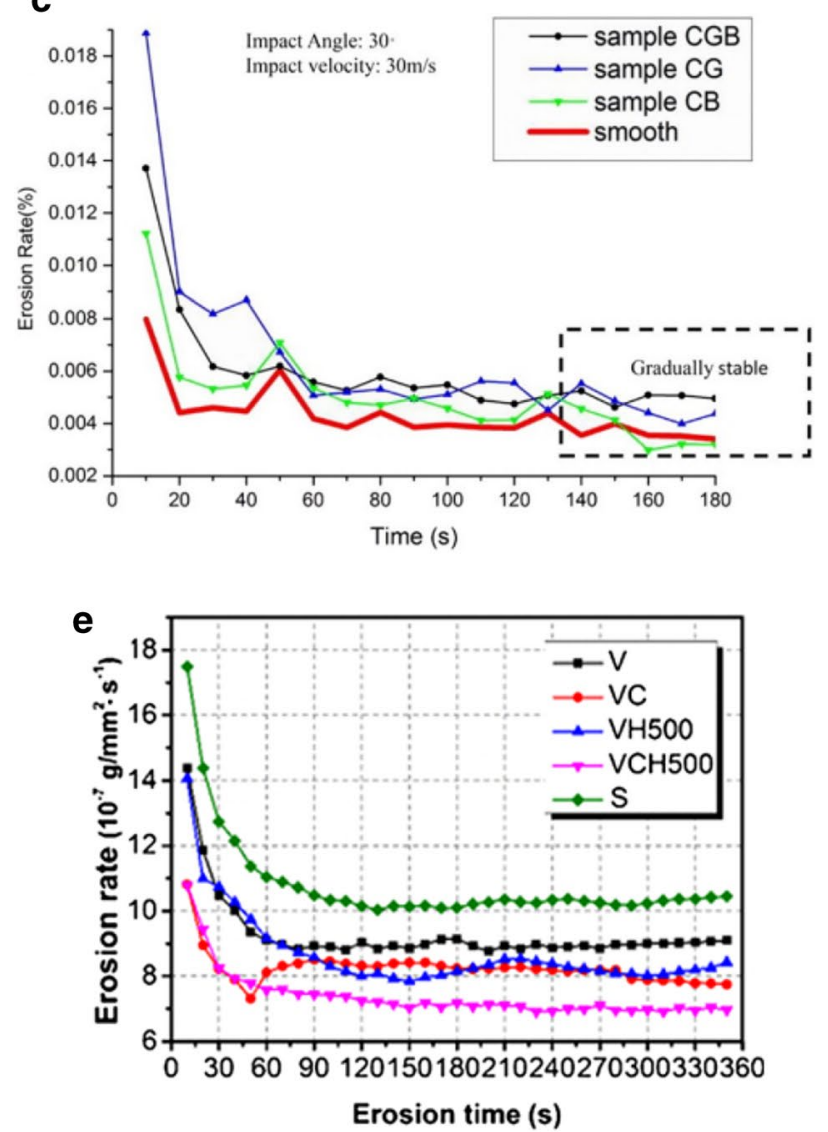

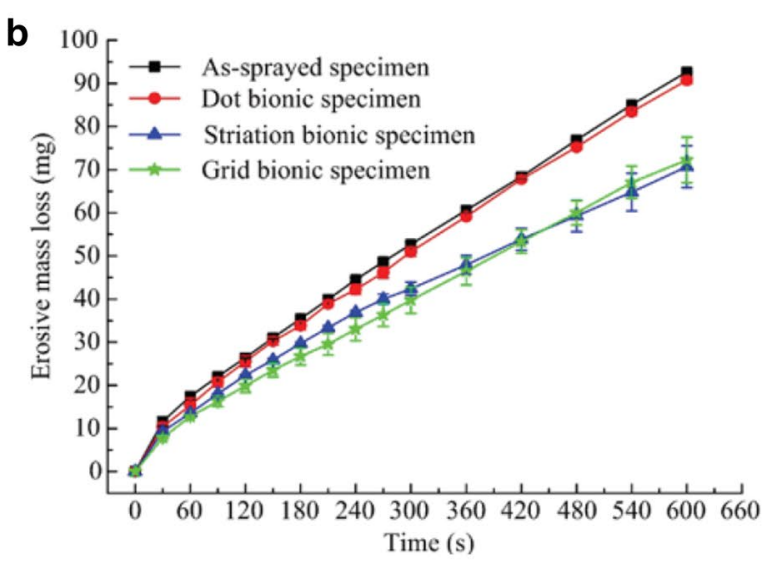

d
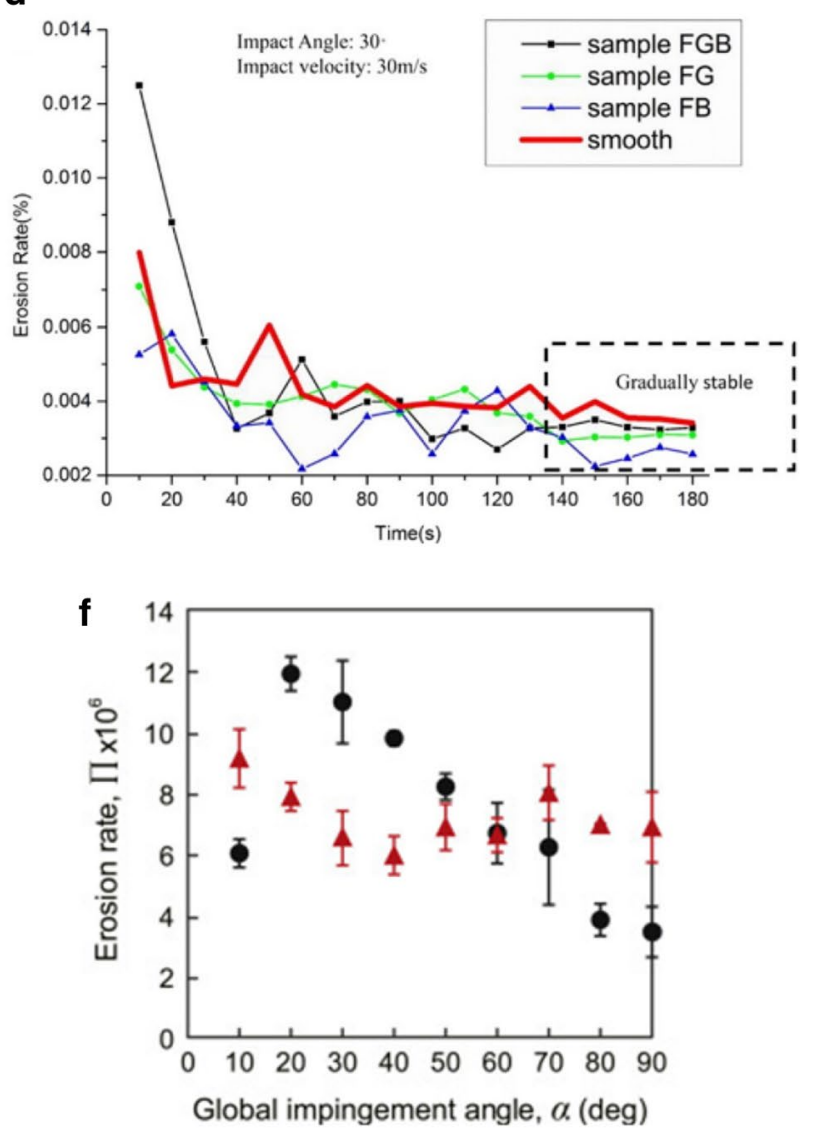

Figure 11 (a) The erosion rate of the groove samples with different shapes [61]; (b) The erosion rate of the pit samples with different arrangements [97]; (c) The erosion rate of the samples with composite structures, C stands for curve, G stands for groove, and B stands for bump [66]; (d) The erosion rate of the samples with composite structures, F stands for flat, $\mathrm{G}$ stands for groove, and B stands for bump [66]; (e) The erosion rate of the samples with composite structures, $\mathrm{V}$ stands for groove, $\mathrm{C}$ stands for convex hull (bump), $\mathrm{H}$ stands for hexagonal pit, $\mathrm{S}$ stands for smooth, and 500 stands for the size of a pit [19]; (f) The erosion rate of the groove samples and smooth samples at different impact angles [63]

have been greatly improved. In recent years, many studies on the fabrication of new bio-inspired materials by mimicking the extraordinary inner structure have been performed, and the preparation methods of these materials are various. Next, the bio-inspired materials with brick and mortar structure or twisted plywood structure are separately discussed.

Mimicking the inner structure of nacre, bio-inspired materials with brick and mortar structure were fabricated by different methods [71, 73, 87]. Freeze-casting is 
inspired by the freezing process of seawater (Figure 12a) $[67,98-101]$, and the common approach of freeze-casting is as follows. When a ceramic slurry is frozen, ceramic particles are repelled from the ice-water interface as the ice front grows and settle down [98]. After sintering, the target inner architecture is formed [67, 98]. Then, an organic or inorganic phase is used to fill the void space to yield a two-phase nacre-like composite structure, which can dramatically promote the strength and fracture toughness of bio-inspired materials [98]. Additive manufacturing provides a new path towards fabricating bio-inspired structural materials (Figure 12bi, bii). Different compositions were used to build layered structures, and the preparation process was precisely controlled by a computer [102, 103]. Different proportions of compositions could be achieved by controlling the supply of different compositions, and the dimensions of the structural unit could also be precisely controlled [103]. Coextrusion is another bulk processing technique to make bio-inspired materials with brick and mortar structure (Figure 12c). In the process of coextrusion, a feed rod with specific core and shell diameters is produced, and the cross section of the rod is reduced down to a filament to preserve the aspect ratio during the extrusion process. Then, the filament is divided into many single pieces, representing individual "bricks" in the brick and mortar structure [104]. Additionally, coextrusion technology can control the volume of mortar precisely coated on a brick to achieve high-ceramic/low-mortar volume fractions [104]. Self-assembly is another alternative approach that has been used to fabricate bio-inspired materials with brick and mortar structure (Figure 12di). The extraordinary inner structure of the nanocomposite consists of iron oxide nanoparticles, which are linked with each other due to the thermally induced crosslinking reaction of oleic acid molecules [105]. Recently, mineralization was also used to manufacture nacre-like bulk composites (Figure 12e). A predesigned laminated structure with a chitosan matrix was first prepared by freezing-induced assembly, and the matrix was acetylated and transformed to $\beta$-chitin [106]. Then, the acetylated matrix was mineralized via the decomposition of $\mathrm{Ca}\left(\mathrm{HCO}_{3}\right)_{2}$; in the end, through the process of silk fibroin infiltration and hotpressing, the final bio-inspired material was obtained
[106]. Other methods can be used to fabricate nacre-like materials, such as layer-by-layer, spin-coating, electromagnetic deposition and thermal spray methods [87], but they are not very effective in the preparation of bulk materials.

Some of the above methods that can fabricate nacrelike materials can also be used to prepare bio-inspired materials with twisted plywood structure, such as additive manufacturing and self-assembly [87, 107, 108]. Twisted plywood structure and herringbone-modified twisted plywood structure could be manufactured with a multimaterial 3D printer (Figure 12biii, biv); a stiff acrylic polymer acted as the fibers and a soft elastomeric polymer acted as the matrix in the bio-inspired material [107]. The chiral nature of chitin nanowhiskers was taken advantage of to drive self-assembly of the formation of a chiral nematic phase, and the self-assembly occurred only at certain ranges of $\mathrm{pH}$ and concentration (Figure 12dii) [108]. Furthermore, magnetically assisted slip casting is a manufacturing method combining the aqueous-based slip casting process and magnetically directed particle assembly, which can be used to prepare twisted plywood structure (Figure 12f) [109]. In the process of slip casting, particles of a fluid suspension are deposited in a dry porous mold with a predefined geometry, in which the pore dimensions are usually smaller than the size of the particles [109]. As a result of capillary forces, due to the wetting of the pores of the mold, the liquid phase is continuously removed from the suspension, forming a layer of jammed particles (cake layer) near the wall of the mold [109]. An external magnetic field with a specific direction is used to control the arrangement of the as-deposited anisotropic particles in the cake layer to build the bioinspired material with twisted plywood structure [109].

Through these diverse methods, the mechanical properties of these bio-inspired materials are improved to a certain level, and the fracture toughness is the common factor. As shown in Figure 13, the $J-R$ curve approach is used to define the fracture toughness of composites [ 99 , $109]$. The $J-R$ curve of nacre and the synthetic hybrid composites exhibit extensive rising behavior, indicating extensive external toughening [99]. Furthermore, the fracture toughness of the synthetic hybrid composites is better than that of nacre, and the composites with brick

(See figure on next page.)

Figure 12 (a) (i) Schematic diagram illustrating freeze-casting [69], (ii) the bio-inspired material with lamellar alumina [69], (iii) the bio-inspired material with porous chitosan [69]; (b) (i) A flat nacre-like composite prepared by 3D printing [102], (ii) a curved nacre-like composite prepared by 3D printing [102], (iii) helicoidal structure prepared by 3D printing [107], (iv) herringbone structure prepared by 3D printing [107]; (c) (i) Schematic diagram illustrating coextrusion [104], (ii) singlepass coextrusion counterparts SP-chop [104], (iii) multipass coextrusion counterparts MP-chop [104]; (d) (i) SEM image of the fracture surface of a nacre-like composite prepared by self-assembly [105], (ii) SEM image of the cross section of a chitin/PAA organic template sample with the twisted plywood structure prepared by self-assembly [108]; (e) (i) Schematic diagram illustrating mineralization [106], (ii) SEM image of the fracture surface of synthetic nacre [106], (iii) SEM image of the aragonite layer of synthetic nacre [106]; (f) (i) Schematic diagram illustrating magnetically assisted slip casting [109], (ii) SEM image of the architecture of the periodic platelet [109] 

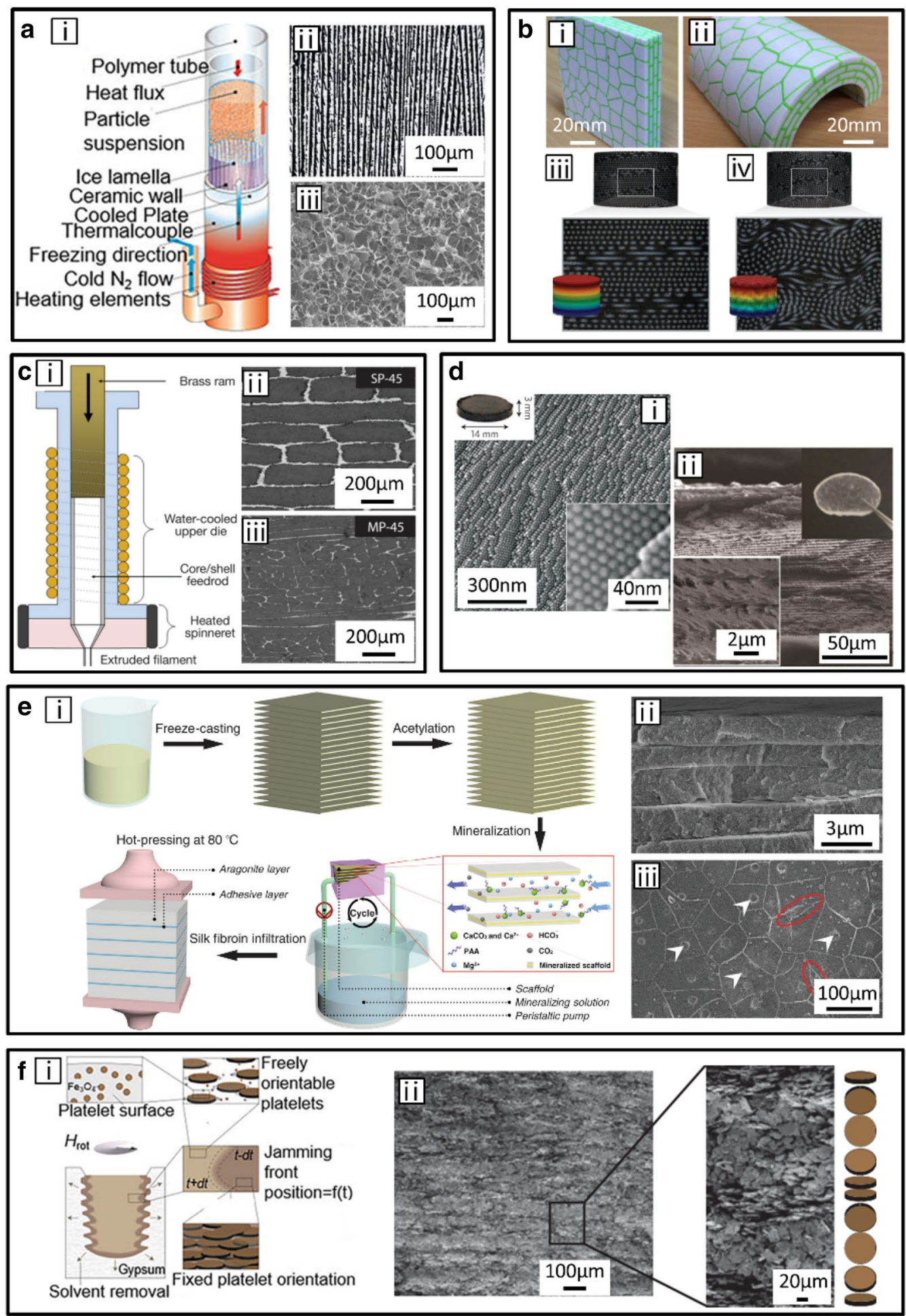

and mortar structure possess the best external toughening (Figure 13a) [99]. Similarly, the composites with twisted plywood structure also have excellent toughness to resist the propagation of cracks (Figure 13b) [109]. As shown in the crack growth resistance curves of the various composites, the rising $J-R$ curves indicate that the 

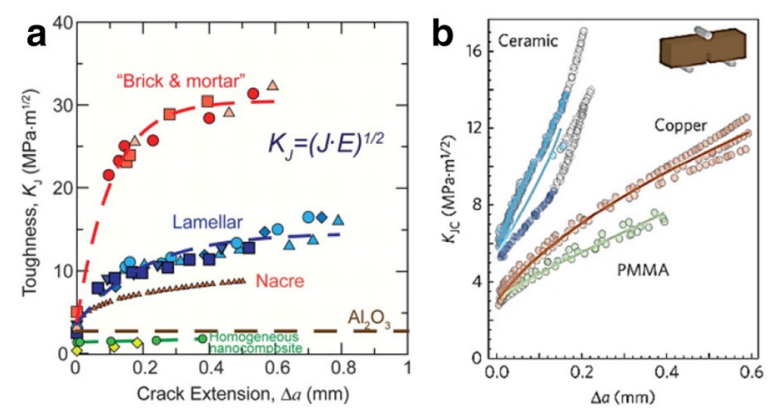

Figure 13 (a) The exception toughness of the composites with different structures [99]; (b) The crack growth resistance curves of the composites with anisotropic structure [109]

fracture toughness of the composites with twisted plywood structure remarkably increases [109]. In general, by imitating the extraordinary inner structure of natural materials, the bio-inspired materials exhibit excellent crack growth resistance, which contributes to the improvement of the fracture toughness. The fracture toughness is a key factor affecting the solid particle erosion resistance of materials, especially for brittle materials. Under the same conditions of the other factors, the erosion rate of materials will decrease as the fracture toughness increases. Due to the improvement of the fracture toughness, the bio-inspired materials have good solid particle erosion resistance. For the solid particle erosion of materials, bio-inspired materials with extraordinary inner structures are an effective solution. However, bio-inspired materials with extraordinary inner structures also have some shortcomings in solid particle erosion resistance because some challenges in the preparation of large area structural materials remain. At present, realizing the industrialized production of bioinspired materials with extraordinary inner structures is difficult.

\subsection{Bio-inspired Anti-solid Particle Erosion Materials with Buffered Structure}

According to the dorsal skin of the desert lizard, after reasonable simplification (Figure 14a), a bionic sample was designed (Figure 14b). 1060 aluminum alloy sheets with a size of $10 \mathrm{~mm} \times 10 \mathrm{~mm}$ were used to replace the upper shell of the scales, which were reversed and placed in the bottom of a $5 \mathrm{~mm}$ deep mold [90]. A mixture of liquid silicone rubber and curing agent was used instead of the soft core of the scales, which was poured into the mold and compacted with a cover board. After it was completely solidified, the bionic sample was demolded from the mold [90]. Plastic balls with diameters of $6 \mathrm{~mm}$ were used for the erosion test. According to the velocities of the plastic balls before and after the impact, the kinetic energy loss rate of the plastic balls impacting the bionic sample was approximately $56.5 \%$, while the kinetic energy loss rate of the contrast sample was approximately $31.2 \%$. The buffered structure can obviously absorb more kinetic energy during the impact process [90]. Compared with the contrast sample, the solid particle erosion resistance of the bionic sample is improved by $10 \%$ after reaching the steady-state period (Figure 14c) [24, 90]. Similarly, some bionic samples with both buffered structure and special surface structure were also produced by template method or 3D printing method [58, 65, 91]. These coupled structure materials exhibited better solid particle erosion resistance than single special surface structure materials due to the existence of the soft layer $[58,65]$.

The buffered structure obviously has ability to improve the solid particle erosion resistance of bio-inspired materials. In the impact process, more energy dissipation means less stress concentration at the impact positions of particles. For ductile materials, the plastic deformation decreases, and for brittle materials, the probability of crack generation also decreases, which improves the solid particle erosion resistance of bio-inspired materials. However, the application of buffered structures also has some limitations. For example, such structures are not suitable for surfaces that require long periods of strength because long-term compression will cause the soft layer of the buffered structure to lose its elasticity, and the elastic soft layer is the foundation of the buffered structure.

\subsection{Bio-inspired Anti-solid Particle Erosion Materials with Self-healing Structures}

In skin and bone, through the vascular system, healing substances can be transported to damaged sites. Mimicking the vascular system, two types of structures can be designed for the self-healing of materials, the microcapsule structure and microvascular structure $[28,110$ 113]. Both of these structures are inspired by the vascular system of skin or bone, and both have good self-healing capability when damage occurs. For the microcapsule structure, the healing material is wrapped into capsules that are stored inside a matrix material, and the capsules rupture with the expansion of internal cracks when the matrix material is damaged, thereby releasing the healing material, which flows into the cracks and comes into contact with an embedded catalyst $[95,110,114]$. Through the polymerization and solidification between these two substances, the damage of the matrix material is repaired [95, 110, 114]. However, the microcapsule structure is not suitable for repeated self-healing because the capsules can only be used once [110, 115]. Furthermore, the catalyst can also be encapsulated in a microcapsule. Under the action of an external force, the microcapsules 

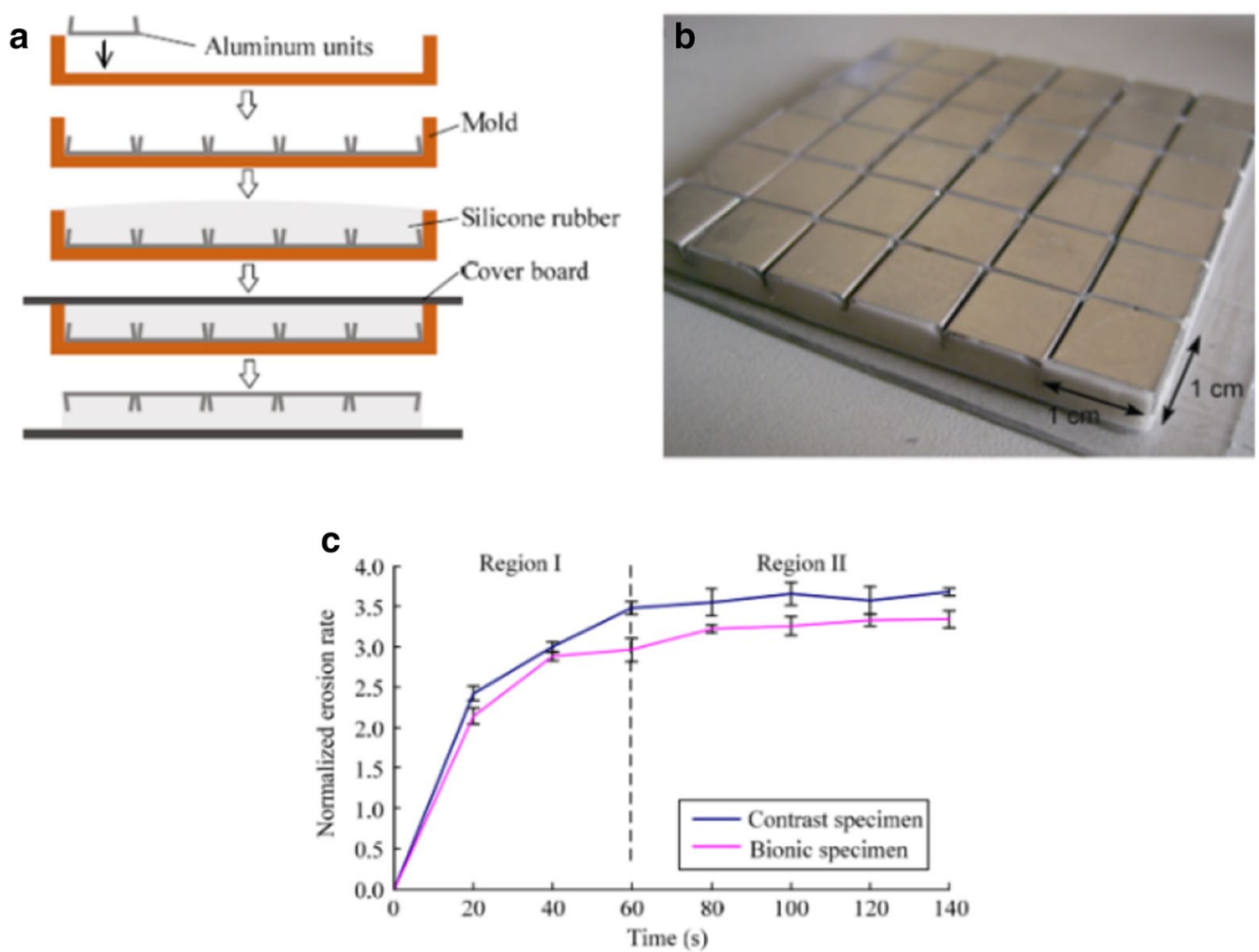

Figure 14 (a) The fabrication procedure of a bionic sample with the buffered structure [90]; (b) The bionic sample with the buffered structure [90]; (c) The erosion rate of the bionic sample with the buffered structure and a contrast sample [90]

break and release the healing material and catalyst, which then undergo a curing reaction to achieve the self-healing process of the matrix material $[116,117]$. For some special materials, catalysts are not necessary, and the action of the healing material can achieve the purpose of self-healing [118, 119]. Similarly, for the microvascular structure, a healing material that is wrapped into microchannels can be delivered to injury sites through its internal microchannels when damage occurs to repair damage of the matrix material $[28,111,112,120-122]$.

The key step in the preparation of a self-healing structure is the formation of the microcapsule or microvascular structure. In situ polymerization of urea-formaldehyde is a common method for preparing microcapsule structures [116, 123-125]. Hollow microcapsules were prepared by the polycondensation reaction of a urea-formaldehyde prepolymer on the surfaces of entrained air bubbles in a reaction vessel. The prepared microcapsules need to be dried and then mixed with the matrix material to produce bio-inspired self-healing materials with a microcapsule structure (Figure 15a) $[116,123-125]$. In addition, the formation methods of the microvascular structure are various. Next, we introduce several common preparation methods of the microvascular structure. The microchannels of the microvascular structure are often prepared with wire [126-128]. In general, wires are first arranged in the matrix material according to a certain arrangement, and these materials are then processed and shaped together. Finally, according to the type of the wires, corresponding measures are taken to remove the wires from the microchannels; thus, the preparation of a bio-inspired material with a vascular structure is completed, and this structure can repair impact damage of the self-healing material (Figure 15b) [126-128]. In the method of assembly of organic ink, organic ink is first deposited into epoxy resin. After the epoxy resin is solidified, the materials are heated to liquefy the organic ink and form microchannels inside the epoxy resin (Figure 15c) [28, 111, 122, 129]. For electrospinning technology, core-shell nanofibers are first fabricated by electrospinning, and then, healing agents are injected into these core-shell nanofibers to form self-healing materials (Figure 15d) [130]. Electrospinning technology can also be used to prepare microcapsule structures [131]. In the evaporation process of sacrificial fibers, sacrificial fibers with a specific position, length, diameter, and curvature are mechanically woven into a preform; then, they are cured and heated to 

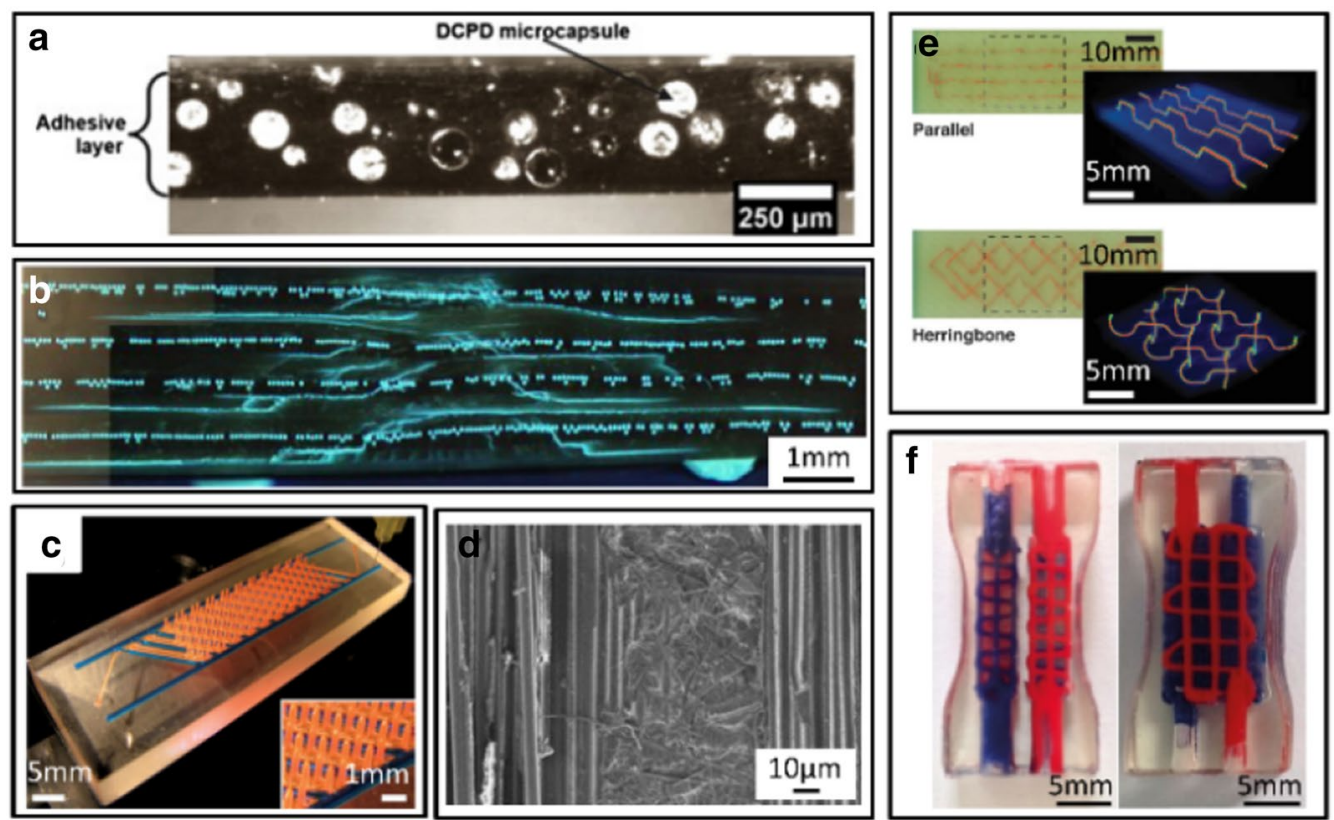

Figure 15 (a) The microcapsule structure in an adhesive layer observed by optical microscopy [123]; (b) The impact damaged cross section of a bio-inspired material with healing filaments [126]; (c) The microvascular network fabricated by assembly of organic ink [129]; (d) SEM micrograph of nanofiber interlayers fabricated by electrospinning [130]; (e) Prevascularized composite laminate samples; X-ray computed microtomographic reconstructions (top) of postvascularized vascular networks (bottom) [132]; (f) Representative image of epoxy-H samples [112]

vaporize the sacrificial fibers and form channels. Finally, a healing material is injected into the formed channels to obtain self-healing composites (Figure 15e) [132, 133]. $3 \mathrm{D}$ printing can also be used to create an inner vascularized structure. A transparent polyvinyl alcohol mold with an inner vascularized structure was printed via a 3D printer, and resins (healing material) were slowly poured into the mold, filling the vessels through capillary action (Figure 15f) [112].

In summary, the mechanical properties of bio-inspired self-healing materials can be repaired by the self-healing structure and healing materials, which avoids further damage to bio-inspired self-healing materials and has a positive effect on improving the solid particle erosion resistance of materials. For materials with the self-healing structure on the surface layer, the effect on the solid particle erosion resistance of the materials is even more pronounced [28, 111, 118, 122, 129]. The standard to measure the self-healing effect is not uniform, and the healing efficiency is the most widely used standard. The healing efficiency is generally defined as the ratio of the fracture toughness of the material for a specific healing cycle to the original fracture toughness; in other words, a good healing efficiency means a high fracture toughness of the healing material $[110-113,116,117,122,129$, $134,135]$. The recovery of the fracture toughness is beneficial for improving the solid particle erosion resistance of materials, and the damage of materials can be repaired multiple times through the self-healing structure with a microvascular structure. For example, for the samples that have a surface material with a self-healing structure, their fracture toughness can be partially restored after the occurrence of damage, although it cannot completely reach the pre-fracture level (Figure 16). The recovery of fracture toughness can inhibit further crack propagation, and when material surfaces are damaged owing to solid particle erosion, the self-healing ability can improve the solid particle erosion resistance of materials. However, the application of this structure also has certain limitations. The repair of damage by the healing material requires a certain amount of time. During this time, cracks continue to expand. Therefore, the application of this structure in continuous working parts is limited.

\section{Applications}

As already described, we can obtain novel bio-inspired anti-solid particle erosion materials inspired by the antisolid particle erosion phenomenon in nature, which can be used in many fields, such as manufacturing, energy, military, and aviation.

Erosion is universal phenomenon in manufacturing industry. Fan is a typical ventilation device, its common types are centrifugal fan, axial fan and mixed-flow fan. 

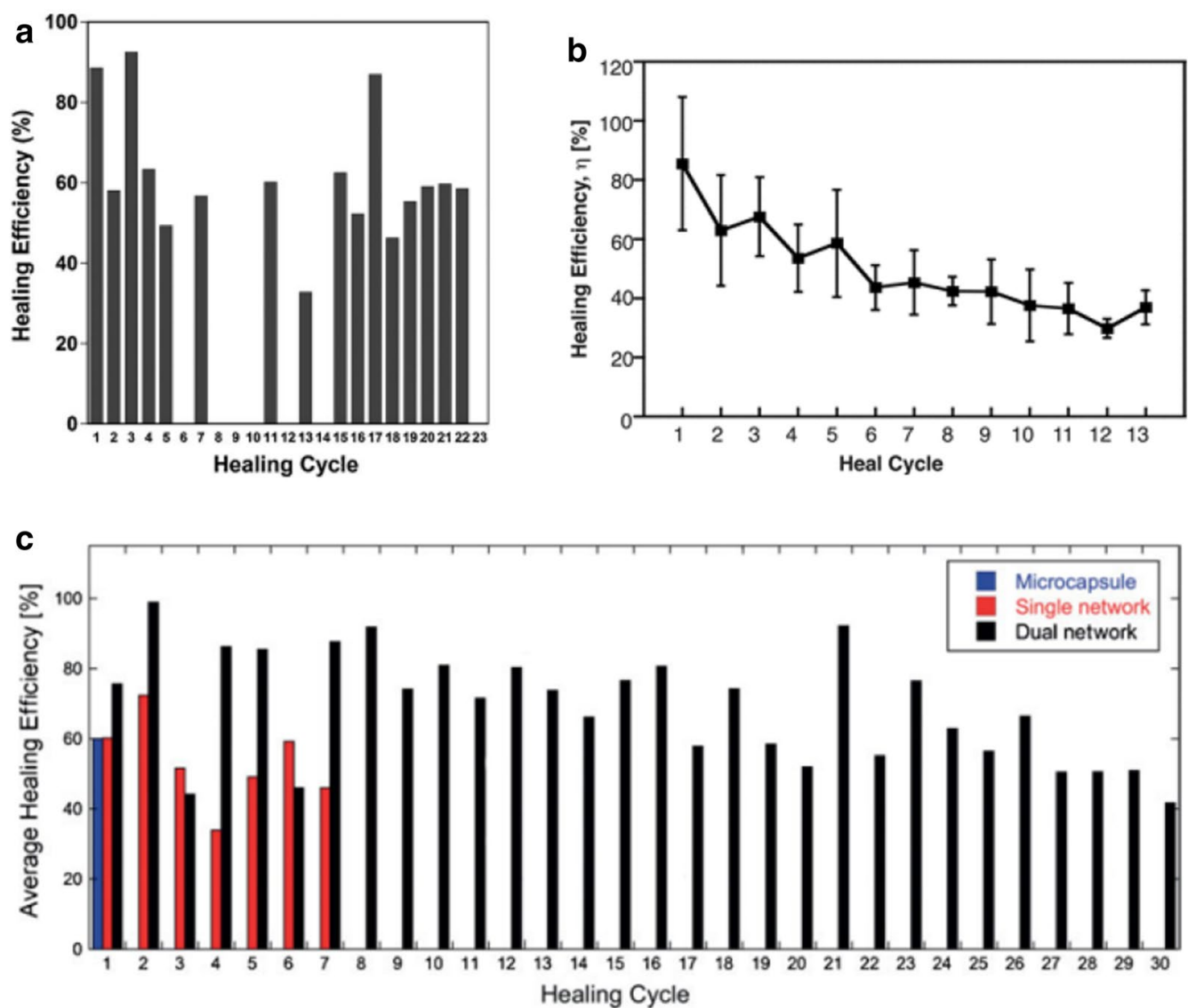

Figure 16 (a) Healing efficiency for each cycle of multinetwork samples [111]; (b) Average healing efficiency for double microvascular samples with error bars [28]; (c) Average healing efficiency for different types of samples over 30 healing cycles [129]

The blades of the fans are eroded by solid particles under dusty conditions, which can bring about blade material loss, decrease of blade chord and reduction of effective camber, leading to a degradation in aerodynamic performance (Figure 17a) [7, 8, 136]. Abrasive jet machining is a non-traditional manufacturing technology based on erosion localization and intensification, which is suitable for cut almost any material without obvious heat damage and thermal stress. Nozzle is a critical part in abrasive jet equipment. The impact of abrasive particles results in serious nozzle erosion, which can cause manifest decreasing precision and jet divergence. Frequent replacement of nozzles not only raises processing cost, but also decreases machining efficiency (Figure 17b) [137-140].

With the development of the modern oil and gas industry, these commodities are traded and transported more frequently (Figure 17c). Today, pipeline transportation is the common way to transport oil and gas, which has significant advantages over other methods of transportation. However, sand is commonly produced during the production of oil and gas [57], and sand can lead to erosion of the pipeline, which is recognized as a main problem in the transportation of oil and gas [3]. Therefore, improving the solid particle erosion resistance of a pipeline can reduce the maintenance costs and bring about huge economic benefits [141]. In addition, with the growth of energy demand, the development and utilization of renewable energy sources, such as wind and water energy, is very necessary [142, 143]. A turbine is the core equipment of wind and water energy conversion. During the operating time of a turbine, the blades of the turbine are impacted by fluids, such as wind and water flow, and solid particles in the fluid erode the blades (Figure 17d, e). Solid particle erosion damages the blade surface, affects the hydrodynamic performance of the turbine and reduces the energy conversion efficiency [144-146]. In particular, in harsh environments, such as sandy areas, this phenomenon will become more serious, and the rated nominal power of turbines can be significantly reduced [143, 146, 147]. Bio-inspired anti-solid particle 

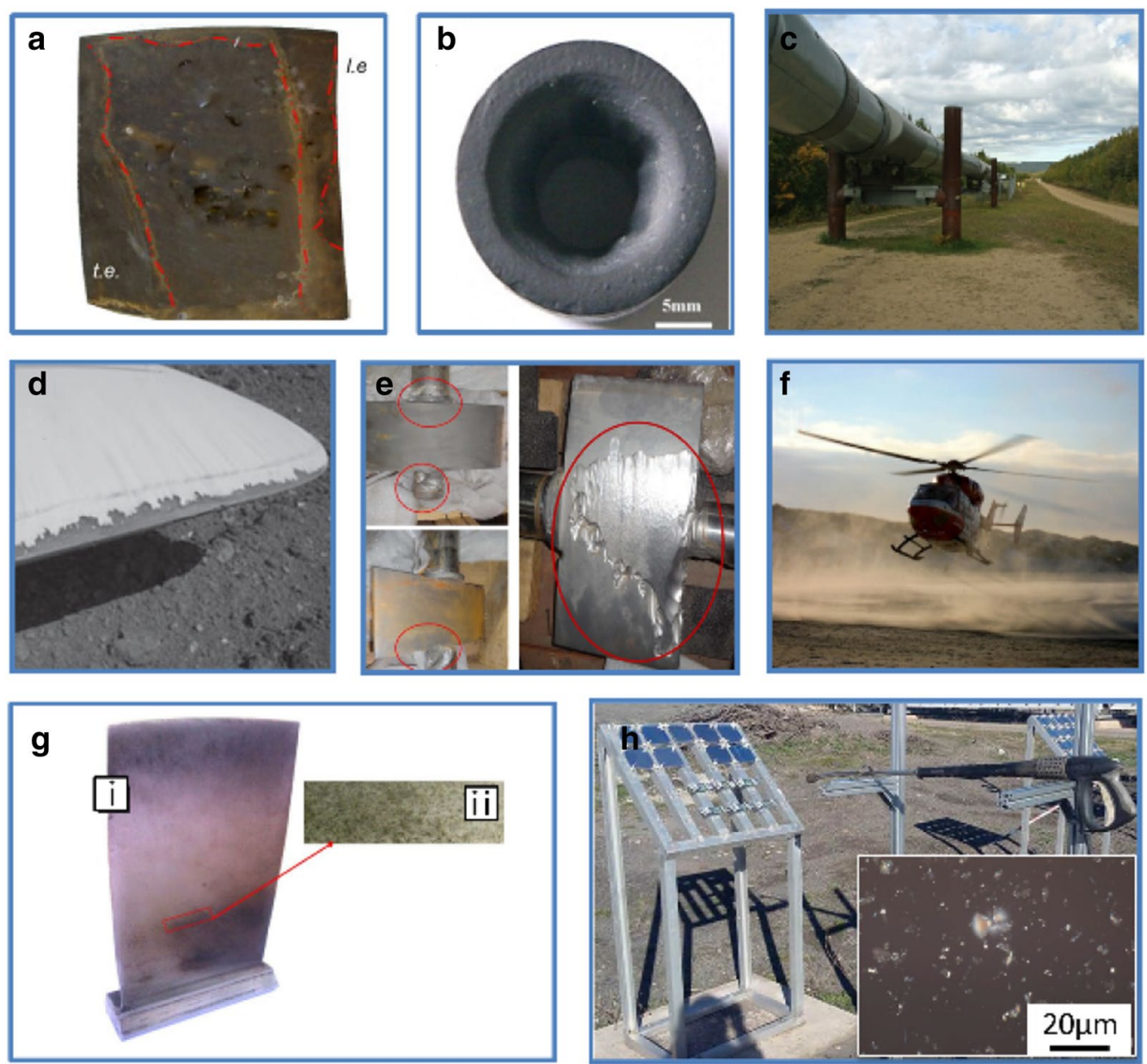

Figure 17 (a) The erosion phenomenon of a fan blade [7]; (b) The erosion behavior of a ceramic nozzle [138]; (c) Conveying pipelines of oil or gas; (d) The erosion phenomenon of a wind turbine blade [144]; (e) Sediment erosion of hydroelectric generator blades [143]; (f) Sand impact on working helicopter blades; (g) The erosion phenomenon of a compressor blade: (i) A blade of compressor [149], (ii) Pits caused by solid particle erosion in the critical zone [149]; (h) The cleaning setup of antireflective glass coatings eroded by a sandstorm; microscope picture of a sample with antireflective coatings after treatment in the sandstorm chamber (inset) [157]

erosion materials may be safely stated to have significant application in the energy field.

In the field of military, due to the particularity and confidentiality of military, military equipment may be located in desert, or may operate in desert. Severe sandstorm in desert can cause great erosion damage to military equipment, which will affect the implementation of military tasks. Therefore, the surfaces of military equipment are required to have the ability to resist wind and sand erosion. For example, when a helicopter is flying in the desert, sand hits the blades of the helicopter at a very high speed (Figure 17f), causing the blades to be strongly eroded by the sand [148]. If we do not take effective measures, once the aircraft blades fail, serious accidents will occur. Similarly, building materials of military base in the desert are need to be able to resist sand. On the whole, bio-inspired anti-solid particle erosion materials can be used to overcome these problems and show unique advantages in the military field.

Solid particle erosion is also a serious problem in the field of aviation. A turbine engine is the core component of jet aircraft, and its working performance plays a vital role in the steady operation of jet aircraft. The impact of small particles on the turbine blades at high speed will cause permanent material loss and irreversible damage of the blades [12,149]. Therefore, as the clearance and blade surface roughness increase (Figure 17g), the blade shape changes (especially the leading and trailing edges), leading to turbine performance decline and maintenance cost increase [150]. When jet aircraft are flown over a volcanic 
eruption area, the solid particle erosion of blades will be more serious $[151,152]$. Undoubtedly, the importance of bio-inspired anti-solid particle erosion materials in the aviation industry for resisting solid particle erosion in the future is self-evident.

With the development of various functional surfaces, their durability has been given increasing attention [153155]. In particular, if functional materials are exposed, solid particle erosion is an important cause of their failure [156]. This erosion can lead to performance degradation or even complete failure of the functional surfaces. For example, solid particle erosion of an antireflective glass coating used for solar energy can reduce its optical properties and service life (Figure 17h) [157]. In addition, solid particle erosion is also a disadvantageous factor affecting other functional surfaces. Therefore, improving the anti-solid particle erosion performance of functional materials is very important, along with the anti-solid particle erosion materials described in this review.

\section{Conclusions and Outlook}

In this review, we have summarized the recent progress in novel bio-inspired anti-solid particle erosion materials. By mimicking the extraordinary structure of natural materials, bio-inspired artificial materials have excellent anti-solid particle erosion performance. First, we have summarized the progress in solid particle erosion resistance theories in recent years. According to these theories, the main factors affecting the solid particle erosion resistance of materials can be divided into the following aspects: particle properties, surface material properties and others. Traditional anti-solid particle erosion solutions usually involve improving the solid particle erosion resistance of materials by improving one or more of the factors mentioned above. These solutions have a certain positive effect in improving the solid particle erosion resistance of materials. However, with the development of society and the economy, especially the development of bionic engineering, some new solutions have been developed to meet the increasing requirements of solid particle erosion resistance. Over hundreds of millions of years of evolution, creatures in nature have evolved near perfect structures to achieve many excellent properties. Therefore, nature is a great source of inspiration for scientists and engineers to imitate natural masterpieces in real-life applications. According to the principles of solid particle erosion resistance, the anti-solid particle erosion solutions of natural creatures can be divided into four categories: special surface structure, extraordinary inner structure, buffered structure and self-healing structure. The corresponding artificial bio-inspired anti-solid particle erosion materials are also divided into four categories as described below.
The first category is the bio-inspired anti-solid particle erosion materials with special surface structures. The special surface structure can be divided into four types: groove, pit, bump and curve. Such a structure improves the solid particle erosion resistance of biomaterials by changing the velocity and trajectory of impact particles and the erosion area of material surfaces. In practical applications, artificial bio-inspired materials with special surface structures have excellent anti-solid particle erosion performance compared to smooth surfaces. Different surface structures have different effects on the solid particle erosion resistance, and the groove has the most significant effect. In addition, the size of the structure also affects the solid particle erosion resistance of materials.

The second category is bio-inspired anti-solid particle erosion materials with extraordinary inner structures. The extraordinary inner structure contains two types: the brick and mortar structure and twisted plywood structure. During the fracture process of biomaterials, these extraordinary inner structures lead to energy dissipation, which can significantly improve the fracture toughness of biomaterials. Artificial bio-inspired materials inspired by the extraordinary inner structure also exhibit excellent fracture toughness. The improvement of fracture toughness is accompanied by the improvement of the solid particle erosion resistance of the materials, especially for brittle materials.

The third category is bio-inspired anti-solid particle erosion materials with buffered structures. The buffered structure consists of a hard layer and a soft layer. When solid particles impact the hard layer, the soft layer below the hard layer absorbs part of the kinetic energy of the particles. Correspondingly, the energy used for erosion is reduced, thus improving the solid particle erosion resistance of the biomaterials. Due to the energy consumption of the buffered structure, the solid particle erosion resistance of artificial bio-inspired materials mimicking the buffered structure of the lizard is improved.

The fourth category is bio-inspired anti-solid particle erosion materials with self-healing structures. The selfhealing structure is another alternative anti-solid particle erosion solution. In the body of natural creatures, when injury occurs, the repair material is transported to injured sites through the self-healing structure, and a chemical reaction occurs to complete the self-healing of injured tissue and prevent further expansion of injury. Two types of self-healing structures have been designed for the self-healing function of artificial materials: the microcapsule structure and microvascular structure. Artificial self-healing materials can restore part of the mechanical properties through the interaction of the self-healing structure and healing substances, which can 
prevent the expansion of cracks and achieve solid particle erosion resistance.

In addition, the rapid development of fabrication technologies provides new opportunities to explore and develop artificial anti-solid particle erosion materials. Artificial materials can be made in many ways. However, to realize the wide application of artificial bio-inspired anti-solid particle erosion materials, we need a general technical method for preparing artificial materials over large areas. Among the various new fabrication technologies, additive manufacturing technologies can be used to fabricate all the above bio-inspired structures, and precise structures can be designed and built using computers. Simultaneously, with the advances of nanotechnologies, the combination of nanotechnologies and additive manufacturing technologies can bring about a new opportunity for the fabrication of large-area artificial anti-solid particle erosion materials in the future. Finally, we also report the potential applications of bio-inspired anti-solid particle erosion materials. These materials can not only be applied to the existing machinery to improve their solid particle erosion resistance but also extend the service life of new bionic functional materials. Learning and drawing inspiration from nature to realize new functional materials is the most promising challenge of the next few years. With the discovery of new biological models and the continuous advancement of manufacturing methods, bio-inspired anti-solid particle erosion materials are believed to have a bright future.

\section{Acknowledgements}

The authors sincerely thanks to Dr. Haiyue Yu and Mr. Dakai Wang of Jilin University for their critical discussion and reading during manuscript preparation.

\section{Authors' Contributions}

SZ wrote the manuscript; JZ, BZ and LR gave some advices on the manuscript; $\mathrm{ZH}$ and $\mathrm{SN}$ assisted with structure and language of the manuscript. All authors read and approved the final manuscript.

\begin{abstract}
Authors' Information
Shuaijun Zhang, born in 1992, is currently a PhD candidate at Key Laboratory of Bionic Engineering (Ministry of Education), Jilin University, China. He received his master degree from Henan Agricultural University, China, in 2018. His current research focuses on bio-inspired anti-erosion materials with micro-nanoscale functional surfaces, and the bionic machinery design and manufacture.
\end{abstract}

Junqiu Zhang, born in 1979, is currently an associate professor at Jilin University, China. He received his PhD degree from Jilin University, China, in 2011. He received his master degree in Jilin University, China, in 2008. His current research focuses on bio-inspired functional surfaces, bio-inspired sensor, and the bionic machinery design and manufacture.

Bin Zhu, born in 1992, is currently a PhD candidate at Department of Mechanical Engineering Sciences, University of Surrey, United Kingdom. He received his master degree from Jilin University, China, in 2018.

Shichao Niu, born in 1986, is currently an associate professor at Jilin University, China. He received his PhD degree from Jilin University, China, in 2014. His current research focuses on bio-inspired anti-fogging materials with micro/ nanoscale hierarchical structures, the diversified optical functional surfaces in nature, bio-inspired functional materials for energy and optical applications and the bionic machinery design and manufacture.

Zhiwu Han, born in 1969, is currently a professor at Jilin University, China. He received his PhD degree from Yanshan University, China, in 1998. He received his master degree in Yanshan University, China, in 1995. His current research focuses on bionic science and engineering, ground mechanical engineering.

Luquan Ren, born in 1944, is an academician of Chinese Academy of Sciences and a professor at Jilin University, China. He received his master degree from Jilin University of Technology, China, in 1981. His main research interests include bionic science and engineering, ground mechanical engineering.

\section{Funding}

Supported by National Key Research and Development Program of China (Grant No. 2018YFA0703300), National Natural Science Foundation of China (Grant Nos. 51835006, 51875244, 51675220, U19A20103), JLU Science and Technology Innovative Research Team (Grant No. 2017TD-04), China Postdoctoral Science Foundation Funded Project (Grant No. 2018T110246), Science and Technology Research Project of Education Department of Jilin Province (Grant Nos. 20190141, JJKH20190135KJ), Joint Construction Project of Jilin University and Jilin Province (Grant No. SF2017-3-4), Scientific and Technological Development Program of Changchun City (Double Ten Project-19SS001), Science and Technology Development Program of Jilin Province (Technology R\&D Project-20190302021GX), Graduate Innovation Fund of Jilin University (Grant No. 2016020), and Postdoctoral Innovative Talent Support Program (Grant No. BX20190139), Joint Fund of the Ministry of Education for Equipment Research (Grant No. 6141A02022131), and Fundamental Research Funds for the Central Universities.

\section{Competing Interests}

The authors declare no competing financial interests.

\section{Author Details}

${ }^{1}$ Key Laboratory of Bionic Engineering (Ministry of Education), Jilin University, Changchun 130022, China. ${ }^{2}$ Department of Mechanical Engineering Sciences, University of Surrey, Guildford, Surrey GU2 7XH, UK.

Received: 26 October 2019 Revised: 13 April 2020 Accepted: 6 May 2020 Published online: 20 May 2020

\section{References}

[1] M A Chowdhury, U K Debnath, D M Nuruzzaman, et al. Experimental analysis of aluminum alloy under solid particle erosion process. Proceedings of the Institution of Mechanical Engineers, Part J: Journal of Engineering Tribology, 2016, 230(12): 1516-1541.

[2] V B Nguyen, Q B Nguyen, Z G Liu, et al. A combined numerical experimental study on the effect of surface evolution on the water-sand multiphase flow characteristics and the material erosion behavior. Wear, 2014, 319(1-2): 96-109.

[3] R E Vieira, A Mansouri, B S McLaury, et al. Experimental and computational study of erosion in elbows due to sand particles in air flow. Powder Technology, 2016, 288: 339-353.

[4] P Okonkwo, R Shakoor, M Zagho, et al. Erosion behaviour of API X100 pipeline steel at various impact angles and particle speeds. Metals, 2016, 6(10): 232.

[5] P P Gohil, R P Saini. Coalesced effect of cavitation and silt erosion in hydro turbines-A review. Renewable and Sustainable Energy Reviews, 2014, 33: 280-289.

[6] H S Grewal, A Agrawal, H Singh. Slurry erosion mechanism of hydroturbine steel: Effect of operating parameters. Tribology Letters, 2013, 52(2): 287-303.

[7] A Corsini, A Marchegiani, F Rispoli, et al. Predicting blade leading edge erosion in an axial induced draft fan. Journal of Engineering for Gas Turbines and Power-Transactions of the ASME, 2012, 134(4): 042601.

[8] A Ghenaiet, S C Tan, R L Elder. Experimental investigation of axial fan erosion and performance degradation. Proceedings of the Institution of Mechanical Engineers Part A-Journal of Power and Energy, 2004, 218(A6): 437-450. 
[9] S Matthews, B James, M Hyland. High temperature erosion-oxidation of $\mathrm{Cr} 3 \mathrm{C} 2-\mathrm{NiCr}$ thermal spray coatings under simulated turbine conditions. Corrosion Science, 2013, 70: 203-211.

[10] S H Chang, T P Tang, KT Huang. Improvement of aluminum erosion behavior and corrosion resistance of AISI H13 tool steel by oxidation treatment. ISIJ International, 2010, 50(4): 569-573.

[11] X L Ji, S Z Yang, J H Zhao, et al. Effect of heat treatment on slurry erosion wear resistance of amorphous Ni-P electrodeposits. Tribology Transactions, 2012, 55(1): 86-90.

[12] A Evstifeev, N Kazarinov, Y Petrov, et al. Experimental and theoretical analysis of solid particle erosion of a steel compressor blade based on incubation time concept. Engineering Failure Analysis, 2018, 87: 15-21.

[13] S Kiakojoori, K Khorasani. Dynamic neural networks for gas turbine engine degradation prediction, health monitoring and prognosis. Neural Computing and Applications, 2016, 27(8): 2157-2192.

[14] JY Huang, S H Li, M Z Ge, et al. Robust superhydrophobic TiO2@fabrics for UV shielding, self-cleaning and oil-water separation. Journal of Materials Chemistry A, 2015, 3(6): 2825-2832.

[15] ZW Han, X M Feng, Z G Guo, et al. Flourishing bioinspired antifogging materials with superwettability: Progresses and challenges. Advanced Materials, 2018, 30(13): 1704652.

[16] ZW Han, Z Z Mu, B Li, et al. A high-transmission, multiple antireflective surface inspired from bilayer 3D ultrafine hierarchical structures in butterfly wing scales. Small, 2016, 12(6): 713-720.

[17] ZW Han, Z B Jiao, S C Niu, et al. Ascendant bioinspired antireflective materials: Opportunities and challenges coexist. Progress in Materials Science, 2019, 103: 1-68.

[18] B C K Tee, A Chortos, A Berndt, et al. A skin-inspired organic digital mechanoreceptor. Science, 2015, 350(6258): 313-316.

[19] J Q Zhang, W N Chen, M K Yang, et al. The ingenious structure of scorpion armor inspires sand-resistant surfaces. Tribology Letters, 2017, 65(3): 110.

[20] ZW Han, W Yin, J Q Zhang, et al. Erosion-resistant surfaces inspired by tamarisk. Journal of Bionic Engineering, 2013, 10(4): 479-487.

[21] F Heinemann, M Launspach, K Gries, et al. Gastropod nacre: Structure, properties and growth - Biological, chemical and physical basics. Biophysical Chemistry, 2011, 153(2-3): 126-153.

[22] J R Wu, Z Qin, L L Qu, et al. Natural hydrogel in American lobster: A soft armor with high toughness and strength. Acta Biomaterialia, 2019, 88: 102-110.

[23] D Raabe, C Sachs, P Romano. The crustacean exoskeleton as an example of a structurally and mechanically graded biological nanocomposite material. Acta Materialia, 2005, 53(15): 4281-4292.

[24] Y H Zhang, H Huang, L Q Ren. Erosion wear experiments and simulation analysis on bionic anti-erosion sample. Science China Technological Sciences, 2014, 57(3): 646-650.

[25] R D Maladen, Y Ding, C Li, et al. Undulatory swimming in sand: Subsurface locomotion of the sandfish lizard. Science, 2009, 325(5938): 314-318.

[26] W B Wu, C Lutz, S Mersch, et al. Characterization of the microscopic tribological properties of sandfish (Scincus scincus) scales by atomic force microscopy. Beilstein Journal of Nanotechnology, 2018, 9: 2618-2627.

[27] G C Gurtner, S Werner, Y Barrandon, et al. Wound repair and regeneration. Nature, 2008, 453(7193): 314-321.

[28] A R Hamilton, N R Sottos, S R White. Self-healing of internal damage in synthetic vascular materials. Advanced Materials, 2010, 22(45): 5159-5163.

[29] H M Slot, E R M Gelinck, C Rentrop, et al. Leading edge erosion of coated wind turbine blades: Review of coating life models. Renewable Energy, 2015, 80: 837-848.

[30] N Miyazaki. Solid particle erosion of composite materials: A critical review. Journal of Composite Materials, 2016, 50(23): 3175-3217.

[31] V Javaheri, D Porter, VT Kuokkala. Slurry erosion of steel-Review of tests, mechanisms and materials. Wear, 2018, 408: 248-273.

[32] I Finnie. Erosion of surfaces by solid particles. Wear, 1960, 3(2): 87-103.

[33] J G A Bitter. A study of erosion phenomena: Part I. Wear, 1963, 6(1): $5-21$.

[34] J G A Bitter. A study of erosion phenomena: Part II. Wear, 1963, 6(3): 169-190.

[35] I M Hutchings. A model for the erosion of metals by spherical particles at normal incidence. Wear, 1981, 70(3): 269-281.
[36] G Sundararajan. A comprehensive model for the solid particle erosion of ductile materials. Wear, 1991, 149(1-2): 111-127.

[37] R Bellman. A Levy, Erosion mechanism in ductile metals. Wear, 1981, 70(1): 1-27.

[38] Y F Wang, Z G Yang. Finite element model of erosive wear on ductile and brittle materials. Wear, 2008, 265(5-6): 871-878.

[39] GVTkachenko, B A Uryukov. Similarity criteria in the erosion theory of brittle materials in abrasive particle flow. Powder Metallurgy and Metal Ceramics, 2008, 47(9-10): 572-576.

[40] I Finnie. Some reflections on the past and future of erosion. Wear, 1995, 186: 1-10.

[41] S Srinivasan, R O Scattergood. Effect of erodent hardness on erosion of brittle materials. Wear, 1988, 128(2): 139-152.

[42] G L Sheldon. Similarities and differences in the erosion behavior of materials. Journal of Basic Engineering, 1970, 92(3): 619-626.

[43] I M Hutchings, R E Winter, J E Field. Solid particle erosion of metals: The removal of surface material by spherical projectiles. Proceedings of the Royal Society A: Mathematical, Physical and Engineering Sciences, 1976, 348(1654): 379-392.

[44] A V Levy, P Chik. The effects of erodent composition and shape on the erosion of steel. Wear, 1983, 89(2): 151-162.

[45] V B Nguyen, Q B Nguyen, Y W Zhang, et al. Effect of particle size on erosion characteristics. Wear, 2016, 348: 126-137.

[46] G P Tilly. A two stage mechanism of ductile erosion. Wear, 1973, 23(1): 87-96.

[47] H Arabnejad, A Mansouri, S A Shirazi, et al. Development of mechanistic erosion equation for solid particles. Wear, 2015, 332: 1044-1050.

[48] TAlam, M Aminul Islam, Z N Farhat. Slurry erosion of pipeline steel: Effect of velocity and microstructure. Journal of Tribology, 2015, 138(2): 021604.

[49] I M Hutchings. Transitions, threshold effects and erosion maps. Key Engineering Materials, 1992, 71: 75-92.

[50] Y I Oka, S Mihara, TYoshida. Impact-angle dependence and estimation of erosion damage to ceramic materials caused by solid particle impact. Wear, 2009, 267(1-4): 129-135.

[51] Q B Nguyen, V B Nguyen, CY H Lim, et al. Effect of impact angle and testing time on erosion of stainless steel at higher velocities. Wear, 2014, 321:87-93.

[52] M Divakar, V K Agarwal, S N Singh. Effect of the material surface hardness on the erosion of AISI316. Wear, 2005, 259(1-6): 110-117.

[53] A W Momber. Fracture toughness effects in geomaterial solid particle erosion. Rock Mechanics and Rock Engineering, 2015, 48(4): 1573-1588.

[54] FW Zok, A Miserez. Property maps for abrasion resistance of materials. Acta Materialia, 2007, 55(18): 6365-6371.

[55] S Amini, A Miserez. Wear and abrasion resistance selection maps of biological materials. Acta Biomaterialia, 2013, 9(8): 7895-7907.

[56] H S Grewal, A Agrawal, H Singh. Identifying erosion mechanism: A novel approach. Tribology Letters, 2013, 51(1): 1-7.

[57] M Parsi, K Najmi, F Najafifard, et al. A comprehensive review of solid particle erosion modeling for oil and gas wells and pipelines applications. Journal of Natural Gas Science and Engineering, 2014, 21: 850-873.

[58] ZW Han, J Q Zhang, C Ge, et al. Erosion resistance of bionic functional surfaces inspired from desert scorpions. Langmuir, 2012, 28(5): 2914-2921.

[59] ZW Han, W Yin, J Q Zhang, et al. Active anti-erosion protection strategy in tamarisk (tamarix aphylla). Scientific Reports, 2013, 3: 3429.

[60] ZW Han, H L Feng, W Yin, et al. An Efficient bionic anti-erosion functional surface inspired by desert scorpion carapace. Tribology Transactions, 2015, 58(2): 357-364.

[61] W Yin, Z W Han, H L Feng, et al. Gas-solid erosive wear of biomimetic pattern surface inspired from plant. Tribology Transactions, 2017, 60(1): 159-165.

[62] J Q Zhang, Z W Han, W Yin, et al. Numerical experiment of the solid particle erosion of bionic configuration blade of centrifugal fan. Acta Metallurgica Sinica-English Letters, 2013, 26(1): 16-24.

[63] S Jung, E Yang, W Jung, et al. Anti-erosive mechanism of a grooved surface against impact of particle-laden flow. Wear, 2018, 406: 166-172.

[64] L M Tian, X M Tian, G L Hu, et al. Effects and mechanisms of surface topography on the antiwear properties of molluscan shells (Scapharca subcrenata) using the fluid-solid interaction method. Scientific World Journal, 2014: 185370. 
[65] J Q Zhang, ZW Han, R F Ma, et al. Scorpion back inspiring sand-resistant surfaces. Journal of Central South University, 2013, 20(4): 877-888.

[66] Z W Han, B Zhu, M K Yang, et al. The effect of the micro-structures on the scorpion surface for improving the anti-erosion performance. Surface and Coatings Technology, 2017, 313: 143-150.

[67] F Bouville, E Maire, S Meille, et al. Strong, tough and stiff bioinspired ceramics from brittle constituents. Nature Materials, 2014, 13(5): 508-514.

[68] M E Launey, R O Ritchie. On the fracture toughness of advanced materials. Advanced Materials, 2009, 21(20): 2103-2110.

[69] U G K Wegst, H Bai, E Saiz, et al. Bioinspired structural materials. Nature Materials, 2015, 14(1): 23-36.

[70] S Askarinejad, N Rahbar. Toughening mechanisms in bioinspired multilayered materials. Journal of the Royal Society Interface, 2015, 12(102): 20140855.

[71] HW Zhao, Z Yang, L Guo. Nacre-inspired composites with different macroscopic dimensions: Strategies for improved mechanical performance and applications. NPG Asia Materials, 2018, 10.

[72] Q F Cheng, L Jiang, ZYTang. Bioinspired layered materials with superior mechanical performance. Accounts of Chemical Research, 2014, 47(4): $1256-1266$.

[73] J S Peng, Q F Cheng. High-performance nanocomposites inspired by nature. Advanced Materials, 2017, 29(45): 1702959.

[74] R O Ritchie. The conflicts between strength and toughness. Nature Materials, 2011, 10(11): 817-822.

[75] S Xia, Z N Wang, H Chen, et al. Nanoasperity: Structure origin of nacreinspired nanocomposites. ACS Nano, 2015, 9(2): 2167-2172.

[76] F Barthelat. Growing a synthetic mollusk shell. Science, 2016, 354(6308): 32-33.

[77] F Song, A K Soh, Y L Bai. Structural and mechanical properties of the organic matrix layers of nacre. Biomaterials, 2003, 24(20): 3623-3631.

[78] A G Evans, Z Suo, R Z Wang, et al. Model for the robust mechanical behavior of nacre. Journal of Materials Research, 2001, 16(9): 2475-2484.

[79] B L Smith, TE Schaffer, MViani, et al. Molecular mechanistic origin of the toughness of natural adhesives, fibres and composites. Nature, 1999, 399(6738): 761-763.

[80] C Sachs, H Fabritius, D Raabe. Influence of microstructure on deformation anisotropy of mineralized cuticle from the lobster Homarus americanus. Journal of Structural Biology, 2008, 161(2): 120-132.

[81] H O Fabritius, C Sachs, P R Triguero. Influence of structural principles on the mechanics of a biological fiber-based composite material with hierarchical organization: The exoskeleton of the lobster homarus americanus. Advanced Materials, 2009, 21 (4): 391-400.

[82] J CWeaver, GW Milliron, A Miserez, et al. The stomatopod dactyl club :A formidable damage-tolerant biological hammer. Science, 2012 , 336(6086): 1275-1280.

[83] R G Yang, A Zaheri, W Gao, et al. AFM identification of beetle exocuticle: Bouligand structure and nanofiber anisotropic elastic properties. Advanced Functional Materials, 2017, 27(6): 1603993.

[84] E A Zimmermann, B Gludovatz, E Schaible, et al. Mechanical adaptability of the Bouligand-type structure in natural dermal armour. Nature Communications, 2013, 4: 2634.

[85] S Nikolov, M Petrov, L Lymperakis, et al. Revealing the design principles of high-performance biological composites using Ab initio and multiscale simulations: The example of lobster cuticle. Advanced Materials, 2010, 22(4): 519-526.

[86] C Sachs, H Fabritius, D Raabe. Hardness and elastic properties of dehydrated cuticle from the lobster Homarus americanus obtained by nanoindentation. Journal of Materials Research, 2006, 21(8): 1987-1995.

[87] N A Yaraghi, D Kisailus. Biomimetic structural materials: Inspiration from design and assembly. Annual Review of Physical Chemistry, 2018, 69: 23-57.

[88] W Baumgartner, F Fidler, A Weth, et al. Investigating the locomotion of the sandfish in desert sand using NMR-Imaging. PLOS ONE, 2008, 3(10): e3309.

[89] R D Maladen, Y Ding, P B Umbanhowar, et al. Mechanical models of sandfish locomotion reveal principles of high performance subsurface sand-swimming. Journal of the Royal Society Interface, 2011, 8(62): 1332-1345.
[90] H Huang, Y Zhang, L Q Ren. Particle Erosion resistance of bionic samples inspired from skin structure of desert lizard, laudakin stoliczkana. Journal of Bionic Engineering, 2012, 9(4): 465-469.

[91] P Liang, Y H Sun, S H Liu, et al. A bionic study on the anti-erosion mechanism of laudakia stoliczkana: Experimental and numerical aspects. Journal of Bionic Engineering, 2019 16(5): 882-893.

[92] J M Garcia-Aznar, C Valero, M J Gomez-Benito, et al. Insights to regenerate materials: Learning from nature. Smart Materials and Structures, 2016, 25(8): 084001.

[93] M J Harrington, O Speck, T Speck, et al. Biological archetypes for selfhealing materials. Advances in Polymer Science, 2016, 273: 307-344.

[94] V Amendola, M Meneghetti. Self-healing at the nanoscale. Nanoscale, 2009, 1(1): 74-88.

[95] C E Diesendruck, N R Sottos, J S Moore, et al. Biomimetic self-healing. Angewandte Chemie-International Edition, 2015, 54(36): 10428-10447.

[96] S C Cowin, L Cardoso. Blood and interstitial flow in the hierarchical pore space architecture of bone tissue. Journal of Biomechanics, 2015, 48(5): 842-854.

[97] P P Zhang, F H Li, X F Zhang, et al. Effect of bionic unit shapes on solid particle erosion resistance of $\mathrm{ZrO}_{2}-7 \mathrm{wt} \% \mathrm{Y}_{2} \mathrm{O}_{3}$ thermal barrier coatings processed by laser. Journal of Bionic Engineering, 2018, 15(3): 545-557.

[98] S Deville, E Saiz, R K Nalla, et al. Freezing as a path to build complex composites. Science, 2006, 311(5760): 515-518.

[99] E Munch, M E Launey, D H Alsem, et al. Tough, bio-inspired hybrid materials. Science, 2008, 322(5907): 1516-1520.

[100] H Bai, FWalsh, B Gludovatz, et al. Bioinspired hydroxyapatite/ poly (methyl methacrylate) composite with a nacre-mimetic architecture by a bidirectional freezing method. Advanced Materials, 2016, 28(1): 50-56.

[101] H Zhang, S H Liu, H P Xiao, et al. Synthesis and tribological properties of bio-inspired nacre-like composites. Materials, 2018, 11(9): 1563.

[102] PTran, T D Ngo, A Ghazlan, et al. Bimaterial 3D printing and numerical analysis of bio-inspired composite structures under in-plane and transverse loadings. Composites Part B: Engineering, 2017, 108: 210-223.

[103] R Yadav, M Naebe, X G Wang, et al. Review on 3D prototyping of damage tolerant interdigitating brick arrays of nacre. Industrial and Engineering Chemistry Research, 2017, 56(38): 10516-10525.

[104] R P Wilkerson, B Gludovatz, J Watts, et al. A novel approach to developing biomimetic ("nacre-like") metal-compliant-phase (nickel-alumina) ceramics through coextrusion. Advanced Materials, 2016, 28(45): 10061-10067.

[105] A Dreyer, A Feld, A Kornowski, et al. Organically linked iron oxide nanoparticle supercrystals with exceptional isotropic mechanical properties. Nature Materials, 2016, 15(5): 522-528.

[106] L B Mao, H L Gao, H B Yao, et al. Synthetic nacre by predesigned matrixdirected mineralization. Science, 2016, 354(6308): 107-110.

[107] N A Yaraghi, N Guarin-zapata, L K Grunenfelder, et al. A sinusoidally architected helicoidal biocomposite. Advanced Materials, 2016, 28(32): 6835-6844.

[108] S Matsumura, S Kajiyama, T Nishimura, et al. Formation of helically structured chitin/ $\mathrm{CaCO}_{3}$ hybrids through an approach inspired by the biomineralization processes of crustacean cuticles. Small, 2015, 11(38): 5127-5133.

[109] H Le Ferrand, F Bouville, T P Niebel, et al. Magnetically assisted slip casting of bioinspired heterogeneous composites. Nature Materials, 2015, 14(11): 1172-1179.

[110] S R White, N R Sottos, P H Geubelle, et al. Autonomic healing of polymer composites. Nature, 2002, 415(6873): 817-817.

[111] K S Toohey, C J Hansen, J A Lewis, et al. Delivery of two-part self-healing chemistry via microvascular networks. Advanced Functional Materials, 2009, 19(9): 1399-1405.

[112] G Postiglione, M Alberini, S Leigh, et al. Effect of 3D-printed microvascular network design on the self-healing behavior of cross-linked polymers. ACS Applied Materials and Interfaces, 2017, 9(16): 14371-14378.

[113] A R Hamilton, N R Sottos, S R White. Pressurized vascular systems for self-healing materials. Journal of the Royal Society Interface, 2012, 9(70): 1020-1028.

[114] I L Hia, V Vahedi, P Pasbakhsh. Self-healing polymer composites: prospects, challenges, and applications. Polymer Reviews, 2016, 56(2): 225-261. 
[115] M W Lee, S An, S S Yoon, et al. Advances in self-healing materials based on vascular networks with mechanical self-repair characteristics. Advances in Colloid and Interface Science, 2018, 252: 21-37.

[116] H H Jin, C L Mangun, D S Stradley, et al. Self-healing thermoset using encapsulated epoxy-amine healing chemistry. Polymer, 2012, 53(2): 581-587.

[117] H Zhang, PW Wang, J L Yang. Self-healing epoxy via epoxy-amine chemistry in dual hollow glass bubbles. Composites Science and Technology, 2014, 94: 23-29.

[118] G L Li, M Schenderlein, Y J Men, et al. Monodisperse polymeric coreshell nanocontainers for organic self-healing anticorrosion coatings. Advanced Materials Interfaces, 2014, 1(1): 1300019.

[119] L Yuan, A J Gu, G Z Liang. A novel cyanate ester resin/microcapsules system. Polymer Composites, 2010, 31(1): 136-144.

[120] R S Trask, C J Norris, I P Bond. Stimuli-triggered self-healing functionality in advanced fibre-reinforced composites. Journal of Intelligent Material Systems and Structures, 2014, 25(1): 87-97.

[121] J F Patrick, N R Sottos, S R White. Microvascular based self-healing polymeric foam. Polymer, 2012, 53(19): 4231-4240.

[122] K S Toohey, N R Sottos, S R White. Characterization of microvascularbased self-healing coatings. Experimental Mechanics, 2009, 49(5): 707-717.

[123] H H Jin, G M Miller, N R Sottos, et al. Fracture and fatigue response of a self-healing epoxy adhesive. Polymer, 2011, 52(7): 1628-1634.

[124] E N Brownt, M R Kessler, N R Sottos, et al. In situ poly(urea-formaldehyde) microencapsulation of dicyclopentadiene. Microencapsulation, 2003, 20(6): 719-730.

[125] E N Brown, S R White, N R Sottos. Retardation and repair of fatigue cracks in a microcapsule toughened epoxy composite-Part II: In situ self-healing. Composites Science and Technology, 2005, 65(15-16): 2474-2480.

[126] R S Trask, I P Bond. Biomimetic self-healing of advanced composite structures using hollow glass fibres. Smart Materials and Structures, 2006, 15(3): 704-710.

[127] R S Trask, I P Bond. Bioinspired engineering study of Plantae vascules for self-healing composite structures. Journal of the Royal Society Interface, 2010, 7(47): 921-931.

[128] CY Huang, R S Trask, I P Bond. Characterization and analysis of carbon fibre-reinforced polymer composite laminates with embedded circular vasculature. Journal of the Royal Society Interface, 2010, 7(49): 1229-1241.

[129] C J Hansen, W Wu, K S Toohey, et al. Self-healing materials with interpenetrating microvascular networks. Advanced Materials, 2009, 21(41): 4143-4147.

[130] X F Wu, A Rahman, Z P Zhou, et al. Electrospinning core-shell nanofibers for interfacial toughening and self-healing of carbon-fiber/epoxy composites. Journal of Applied Polymer Science, 2013, 129(3): 1383-1393.

[131] J H Park, P V Braun. Coaxial electrospinning of self-healing coatings. Advanced Materials, 2010, 22(4): 496-499.

[132] J F Patrick, K R Hart, B P Krull, et al. Continuous self-healing life cycle in vascularized structural composites. Advanced Materials, 2014, 26(25): 4302-4308.

[133] A P Esser-Kahn, P R Thakre, H F Dong, et al. Three-dimensional microvascular fiber-reinforced composites. Advanced Materials, 2011, 23(32): 3654-3658.

[134] Y C Yuan, M Z Rong, M Q Zhang, et al. Self-healing polymeric materials using epoxy/mercaptan as the healant. Macromolecules, 2008, 41(14): 5197-5202.

[135] K S Toohey, N R Sottos, J A Lewis, et al. Self-healing materials with microvascular networks. Nature Materials, 2007, 6(8): 581-585.

[136] A Corsini, F Rispoli, A G Sheard, et al. Numerical simulation of coal fly-ash erosion in an induced draft fan. Journal of Fluids EngineeringTransactions of the ASME, 2013, 135(8): 081303.

[137] X C Chen, S S Deng, J F Guan, et al. Experiment and simulation research on abrasive water jet nozzle wear behavior and anti-wear structural improvement. Journal of the Brazilian Society of Mechanical Sciences and Engineering, 2017, 39(6): 2023-2033.
[138] J X Deng. Wear behaviors of ceramic nozzles with laminated structure at their entry. Wear, 2009, 266(1-2): 30-36.

[139] J X Deng, L L Liu, M W Ding. Erosion wear behaviours of SiC/(W,Ti)C laminated ceramic nozzles in dry sand blasting processes. Materials Science and Engineering A-Structural Materials Properties Microstructure and Processing, 2007, 444(1-2): 120-129.

[140] R Melentiev, F Z Fang. Recent advances and challenges of abrasive jet machining. CIRP Journal of Manufacturing Science and Technology, 2018, 22: 1-20.

[141] A Uzi, Y Ben Ami, A Levy. Erosion prediction of industrial conveying pipelines. Powder Technology, 2017, 309: 49-60.

[142] E Cortes, F Sanchez, A O'Carroll, et al. On the material characterisation of wind turbine blade coatings: The effect of interphase coatinglaminate adhesion on rain erosion performance. Materials, 2017, 10(10): 1146.

[143] R Koirala, B Thapa, H P Neopane, et al. A review on flow and sediment erosion in guide vanes of Francis turbines. Renewable and Sustainable Energy Reviews, 2017, 75: 1054-1065.

[144] A Sareen, C A Sapre, M S Selig. Effects of leading edge erosion on wind turbine blade performance. Wind Energy, 2014, 17(10): 1531-1542.

[145] M Schramm, H Rahimi, B Stoevesandt, et al. The influence of eroded blades on wind turbine performance using numerical simulations. Energies, 2017, 10(9): 1420

[146] B S Thapa, O G Dahlhaugb, B Thapa. Effects of sediment erosion in guide vanes of Francis turbine. Wear, 2017, 390: 104-112.

[147] A Castorrini, A Corsini, F Rispoli, et al. Computational analysis of windturbine blade rain erosion. Computers and Fluids, 2016, 141: 175-183.

[148] G Kim, R Sterkenburg, W Tsutsui. Investigating the effects of fluid intrusion on Nomex ${ }^{\circledR}$ honeycomb sandwich structures with carbon fiber facesheets. Composite Structures, 2018, 206: 535-549.

[149] E Poursaeidi, A M Niaei, M Lashgari, et al. Experimental studies of erosion and corrosion interaction in an axial compressor first stage rotating blade material. Applied Physics A: Materials Science and Processing, 2018, 124(9): 629.

[150] N Casari, M Pinelli, A Suman, et al. EBFOG: Deposition, erosion, and detachment on high-pressure turbine vanes. Journal of TurbomachineryTransactions of the ASME, 2018, 140(6): 061001.

[151] C R Cosher, M G Dunn. Comparison of the sensitivity to foreign particle ingestion of the GE-F101 and P/W-F100 engines to modern aircraft engines. Journal of Engineering for Gas Turbines and Power-Transactions of the ASME, 2016, 138(12): 121201.

[152] R Naraparaju, H Lau, M Lange, et al. Integrated testing approach using a customized micro turbine for a volcanic ash and CMAS related degradation study of thermal barrier coatings. Surface and Coatings Technology, 2018, 337: 198-208.

[153] F R Li, Z R Wang, S C Huang, et al. Flexible, durable, and unconditioned superoleophobic/superhydrophilic surfaces for controllable transport and oil-water separation. Advanced Functional Materials, 2018, 28(20): 1706867.

[154] X HWu, Z Chen. A mechanically robust transparent coating for antiicing and self-cleaning applications. Journal of Materials Chemistry $A$, 2018, 6(33): 16043-16052.

[155] A Das, S Sengupta, J Deka, et al. Synthesis of fish scale and lotus leaf mimicking, stretchable and durable multilayers. Journal of Materials Chemistry A, 2018, 6(33): 15993-16002.

[156] M N Qu, S S Liu, J M He, et al. Bioinspired durable superhydrophobic materials with antiwear property fabricated from quartz sands and organosilane. Journal of Materials Science, 2016, 51(18): 8718-8727.

[157] F Wiesinger, G S Vicente, A Fernandez-Garcia, et al. Sandstorm erosion testing of anti-reflective glass coatings for solar energy applications. Solar Energy Materials and Solar Cells, 2018, 179: 10-16. 